\title{
Prevalence of Existential Vacuum of Writers in the Kurdistan region- Iraq
}

\author{
Yousif H.Salih MOSTAFA ${ }^{1} \&$ Muhammad Taha Hussein BAKR ${ }^{2}$
}

Received: Jun 08, 2018 Reviewed: Nov 01, 2018 Accepted: Nov 15, 2018

\begin{abstract}
The Existential Vacuum is one of the modern concepts in existential psychology. The idea was originally suggested by Viktor Frankl, who defined it as a negative mental state in which a person feels meaninglessness, emptiness, and distress due to an inability to acquire sufficient meaning to resist one's boredom and despair. In the stream of life, a person usually confronts a lot of obstacles and difficulties that may hinder his or her drive to move forward in constructing his entity. Then, success may be one's ally; if one tries to find a meaning from this suffering. Otherwise one shall fail to develop such a meaning, which leads him or her eventually to feel frustrated and endure an extended existential vacuum.
\end{abstract}

Measuring the levels of this existential vacuum in Kurdish writers is an attempt to really understand this vacuum, which, according to new developments in the fields of mental health and existential psychology, fosters a state of despair and boredom in life.

Many studies have shown the importance of this variable in the psychological construction of individuals. The current study is integral to reaching the following goals concerning Kurdish writers: 1) measure the prevalence of existential vacuum and identify statistical significance according to the hypothesis, and 2) measure the differences in existential vacuum prevalence, by age and conservation.

To reach these goals, this article utilizes a tool for measuring existential emptiness created through a review of psychological literature and standards that have been tested in this field. The study sample size reached 159 Kurdish writers from the branches of three governorates (Dahuk, Erbil, and Sulaymaniyah) in Iraqi Kurdistan. This paper comes to the following conclusions by applying its psychometric measurement tool to the acquired sample: 1) there are significant levels of decrease in existential space, after comparing their arithmetic mean with their hypothesis, and2) there are no statistically significant differences in existential vacuum prevalence between the three governorates or between age groups.

Key words: Prevalence of Existential Vacumm, Existential Psychology, Entity, Existential space

\footnotetext{
${ }^{1}$ Prof. Dr, University of Salahaden, College of Arts, Department of Psychology, Erbil, Kurdistan Region- Iraq, E-mail: yousifhsm@gmail.com,

${ }^{2}$ Corresponding Author: Lecturer, University of Salahaden, College of Arts, Department of Psychology, Erbil, Kurdistan Region- Iraq, e-mail: mtahahussein62@gmail.com, ORCID NO: https://orcid.org/0000-0002-02360435
} 


\section{Recommended citation:}

Mostafa, Y. H. S. \& Bakr, M.T.H. (2019). Prevalence of Existential Vacuum of Writers in the Kurdistan region- Iraq. International Journal of Kurdish Studies 5 (1), 121 - 136 DOI: 10.21600/ ijoks.516495

مستويات الفراغ الوجودي لدى الأدباء في أقليم كردستان -العراق

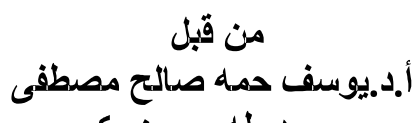

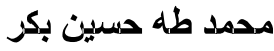

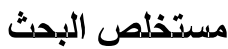

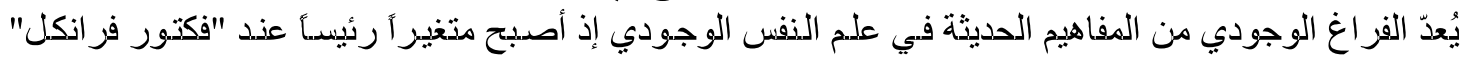

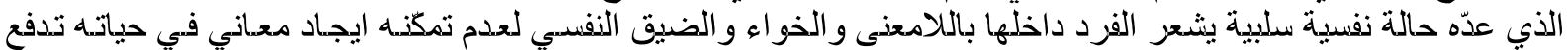

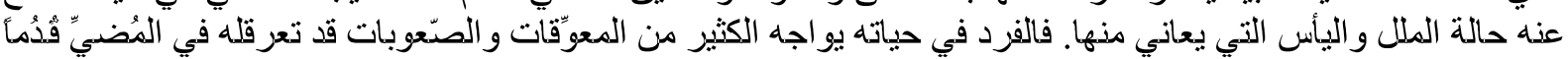

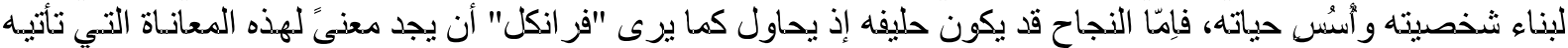

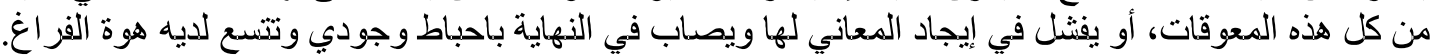

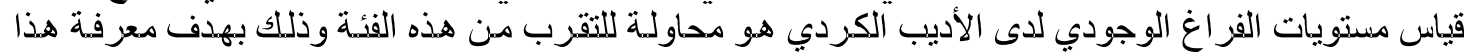

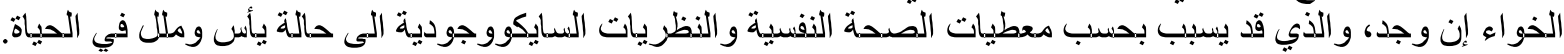

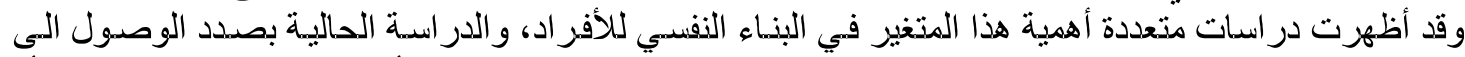

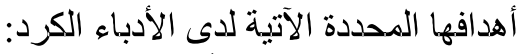

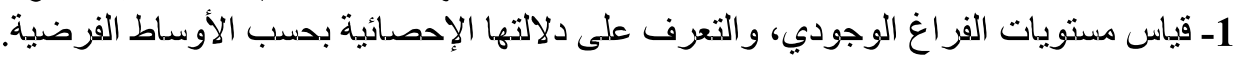

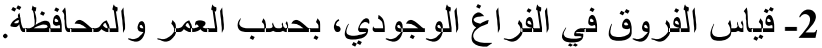

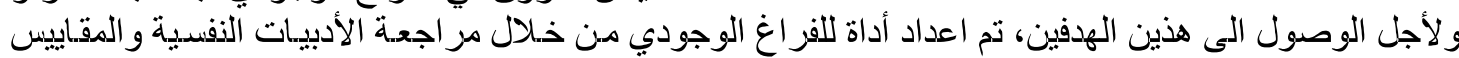

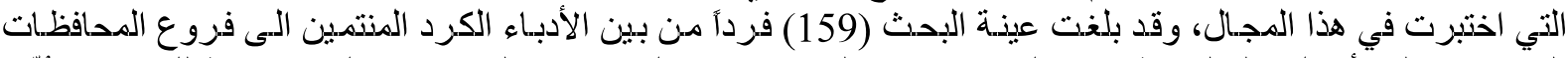

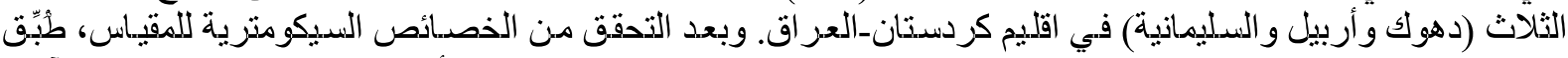

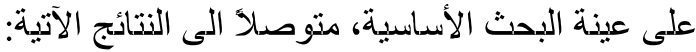

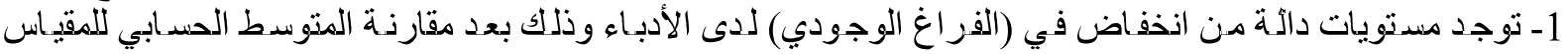
بمتوسطه الفزضي للإينة كلئ.

2- عدم وجود فروق داثة احصائياً في (الفراغ الوجودي) لدى الأدباء بين المحافظات الثثلاثة (دهوك، والسليمانية، وأربيل)، وكذلك في العمر.

مشكلة البحث

الفز اغ الوجودي حالة من الخواء الداخلي يصاب بها الفزد عندما لا يفلح في ايجاد المعاني لمو اقف حياته المتعددة

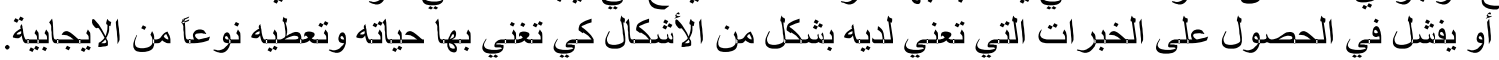

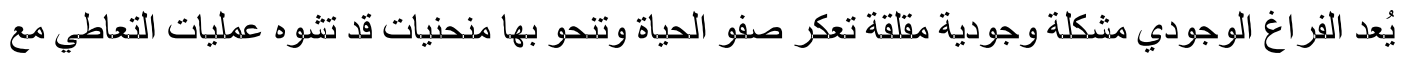
المعطيات التي تو اجه الفرد في بيئاته المتنو عة وتخلق له مطبات تعيقه في ايجاد حياة هانئة وسعيدة نسبياً.

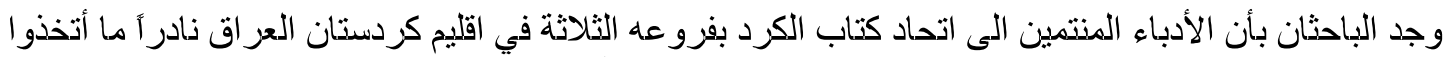

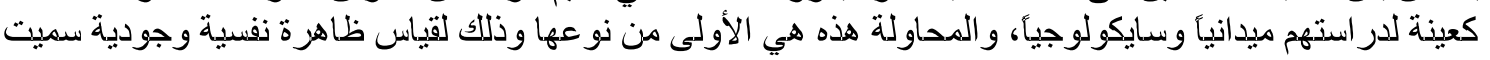




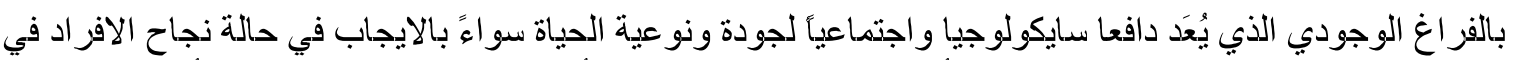

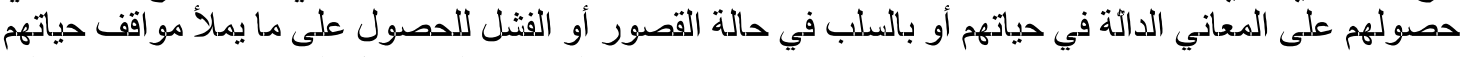
بالخبز ات التي تصل الى مستويات معنوية دالة.

ان حالات الفراغ الوجودي التي بثعر بها الفرد تساهم في خلق معوقات نفسية وأزمات عصدابية و هذا ما قام

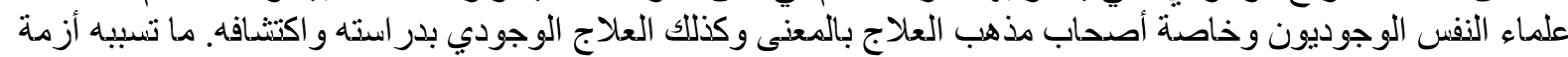

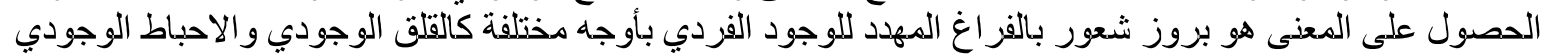

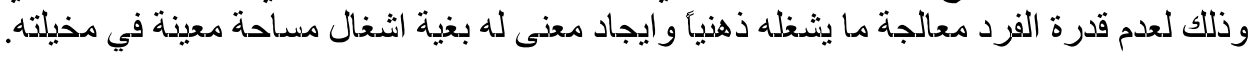

أهمية البحث والحاجة اليه

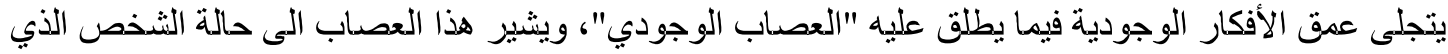

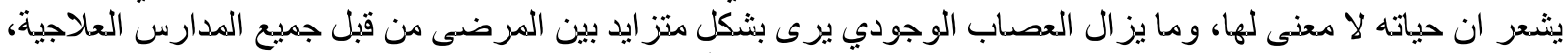

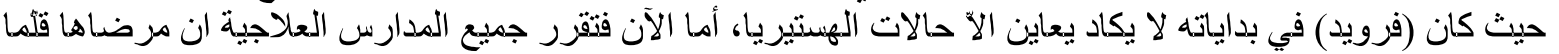
Character Neurosis

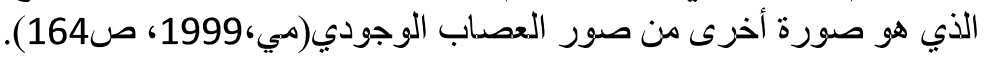

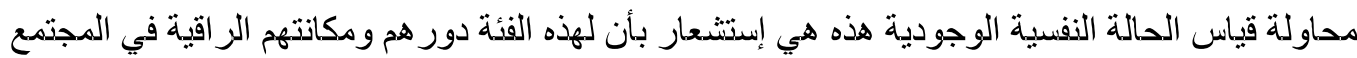

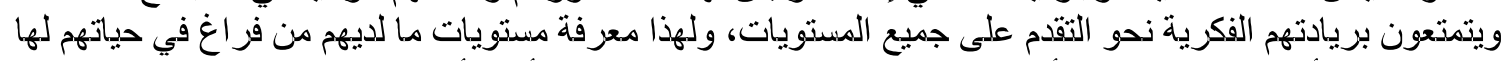

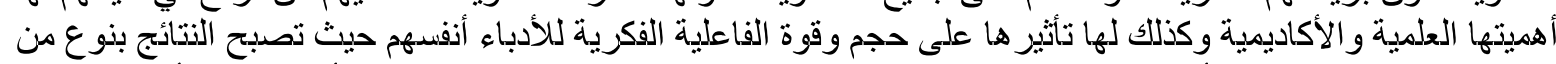

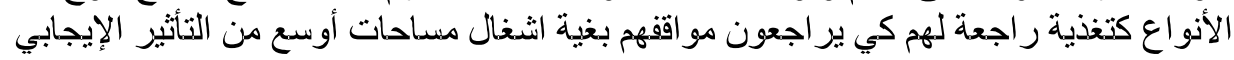

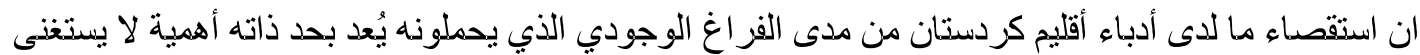

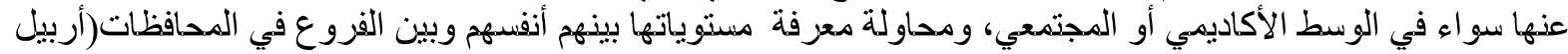
و السليمانية ودهوك) وفي استكثناف جو انب مهمة من الجو انب الكثيرة التي تتمتع بهاً الثخصية الثرية السليمة.

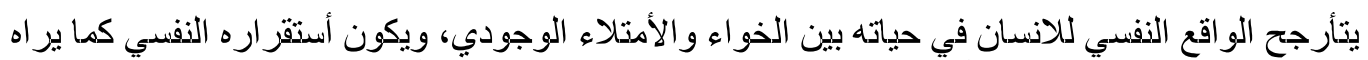

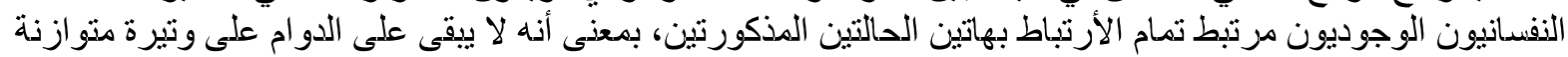

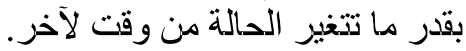

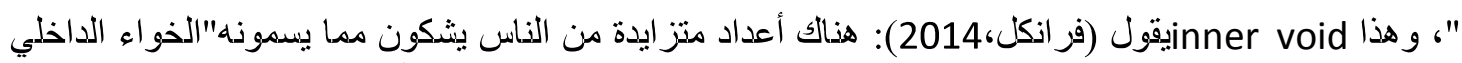

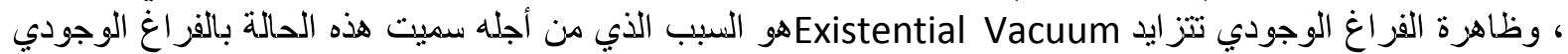

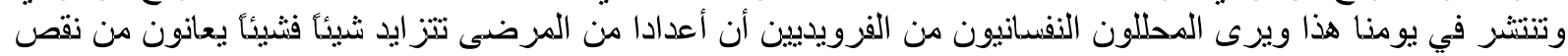

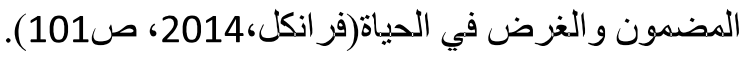

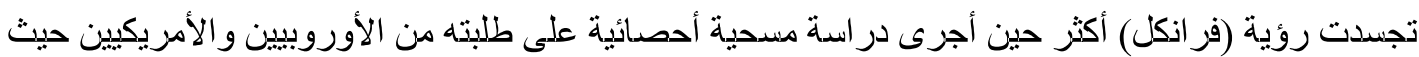

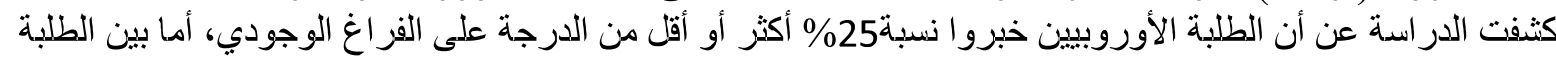

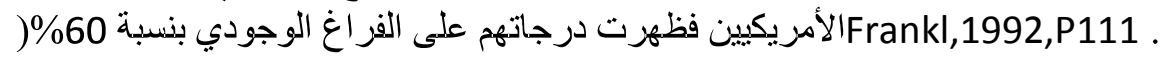

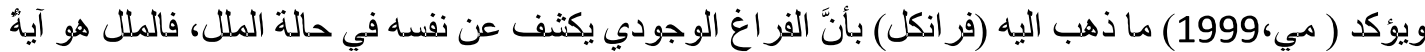

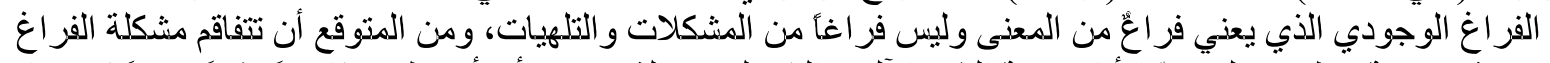

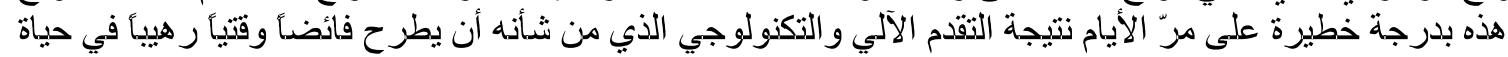

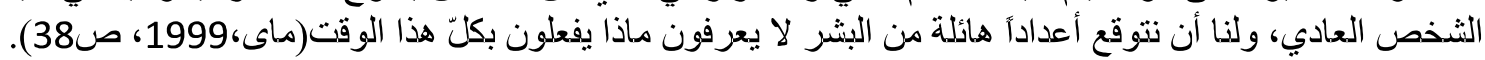

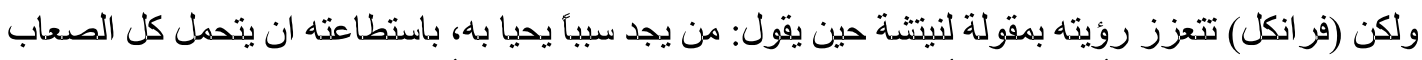

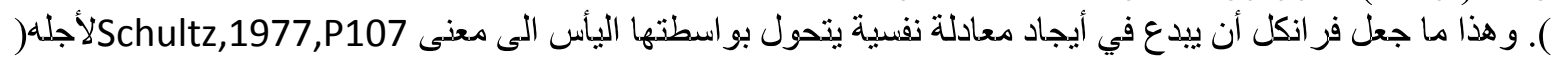
وهي:

$$
\text { اليأس= المعاناة - المعنى }
$$


يقول (جوردون أولبورت) في تقديمه لكتاب فر انكل "الأنسان يبحث عن المعنى" : لكي الكي تعبش عليك أن أن تعاني،

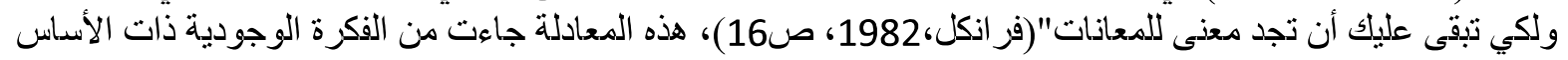

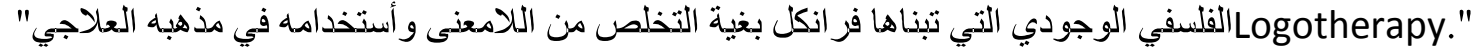

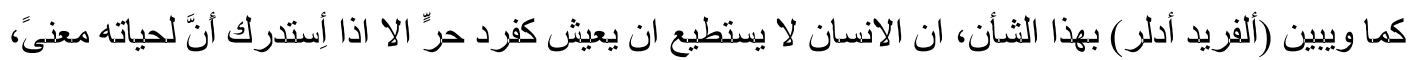

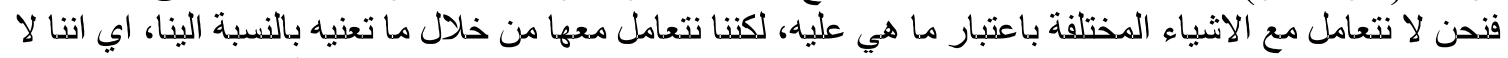

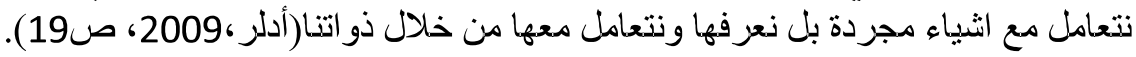

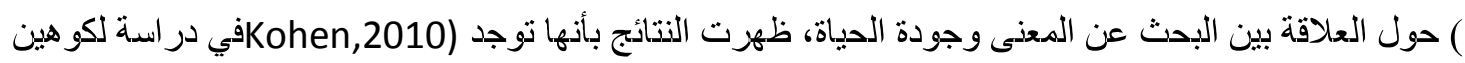

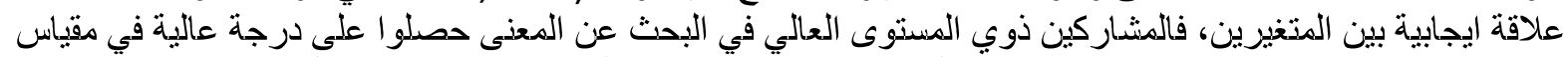

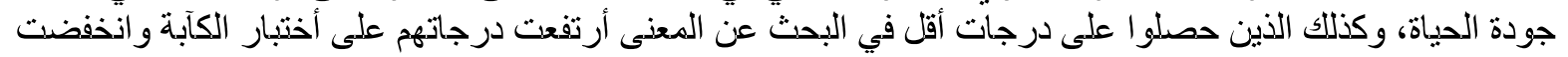
.

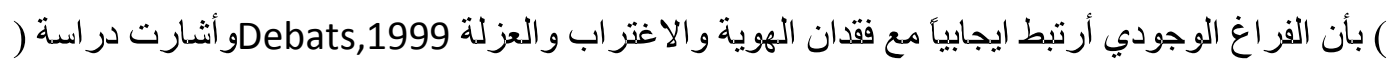

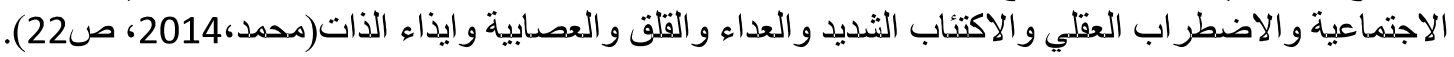

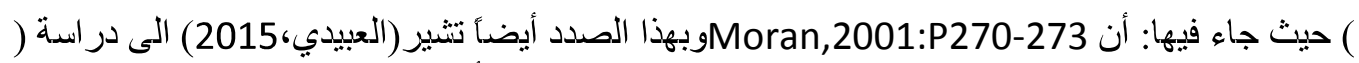

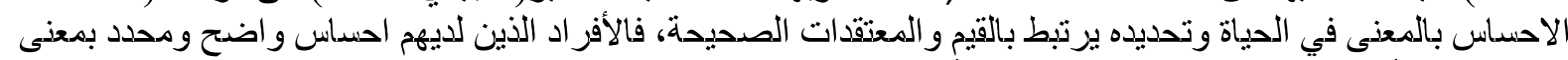

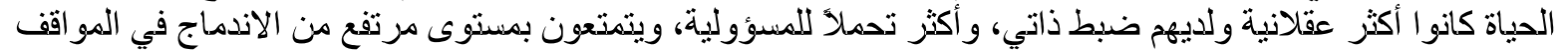

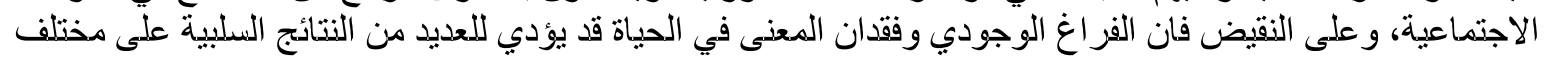

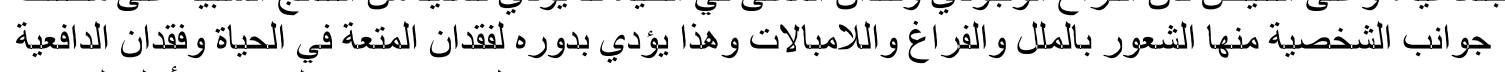

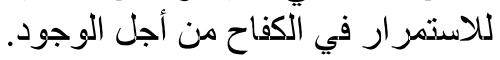

ويستتجج الباحثان بأنَّ أهمية البحث تكمن في جوانب متعددة ومن أبرز ها العينة(الأديب الكردي) التي تمثل شريحة

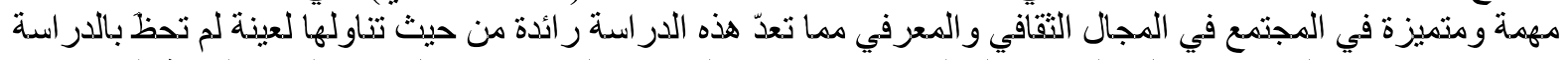

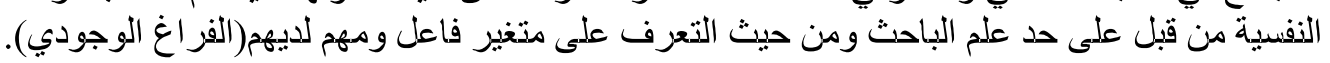

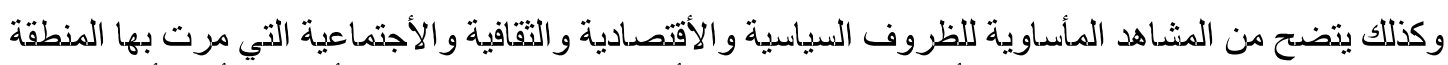

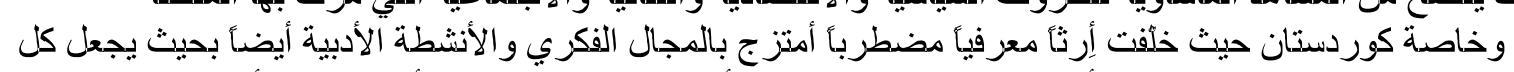

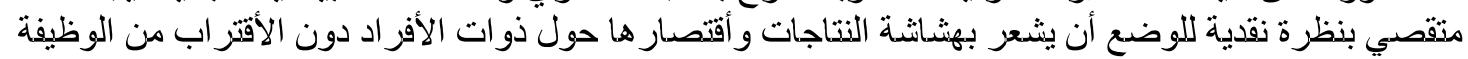

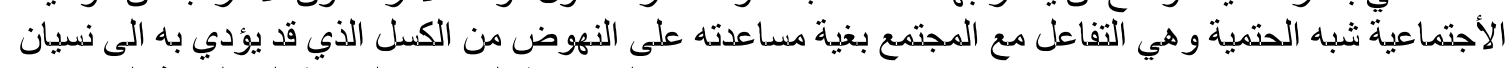

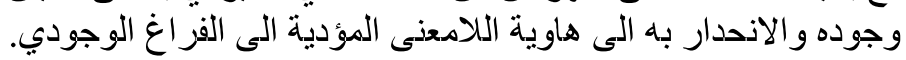

\section{أهداف البحث}

يهدف الباحثان في البحث الحالي الى التعرف على ما يأتي:

1- مستويات الفزاغ الوجودي لدى العينة ككل، والتعرف على دلالاتها بحسب الوسط الفرضي لمقياس الفراغ الوجودي.

2- مستويات الفراغ الوجودي بحسب العمر و المكان.

حدود البحث

تقتصر حدود هذا البحث على أتحادات الكتاب(الأدباء) لمحافظات الأقليم (أربيل و السليمانية ودهوك) سذة 2017. تعريف المصطلحات

\section{1- الفزاغ الوجودي}

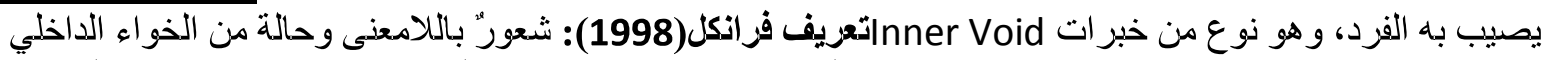

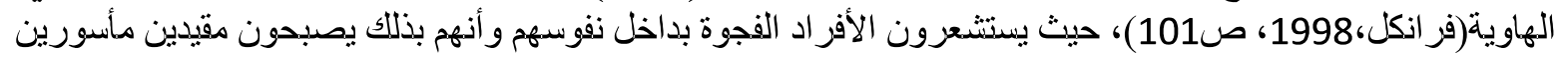

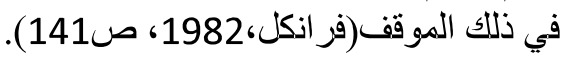

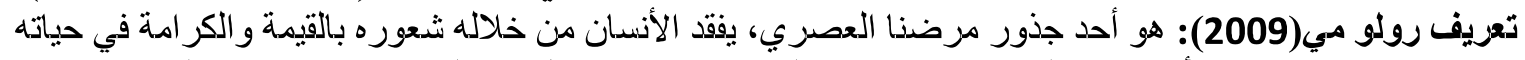

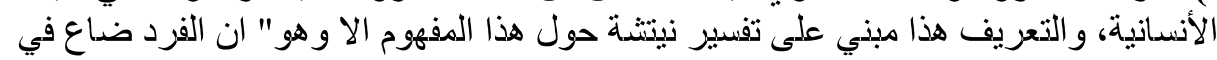

May,2009,P35. ( 
التعزيف الذظري للباحث: حالة من الوهن تصيب مذظومة الوعي لدى الفزد تضعف فيها قدرته على ايجاد المعاني للأثنياء

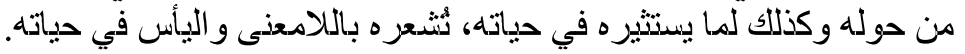

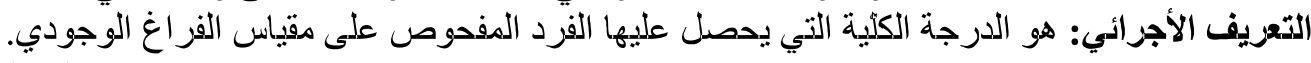

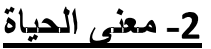

إقتضى تعريف معنى الحياة في البحث الحالي لأنه مفهوم مقتزن بالفز اغ الوجودي الوياة

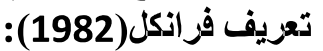

ادر الك فردي مجرد ومميز للفزد لحياته في وقتٍ معين، وطريقة لأفصاحه عن مسؤوليته تجاه الحياة والتعبيز

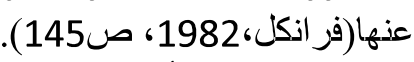

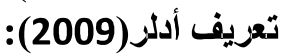

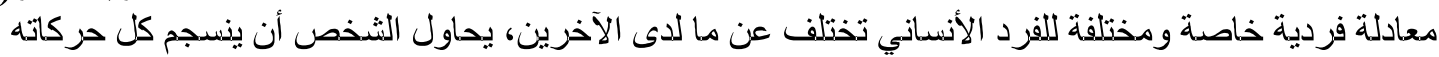

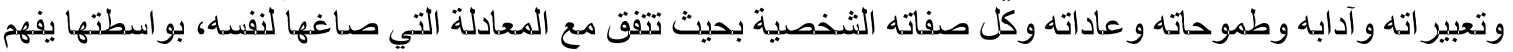

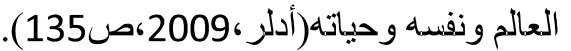

مفهوم الفزاغ الوجودي

الاطار الذظري والدراسدات المتعلقة

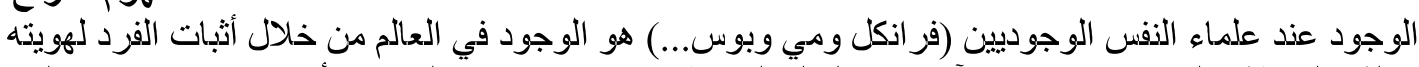

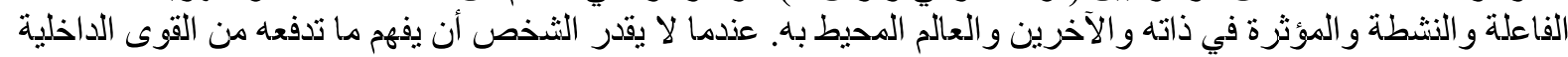

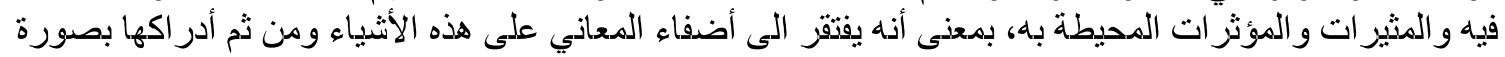
مشوهة.

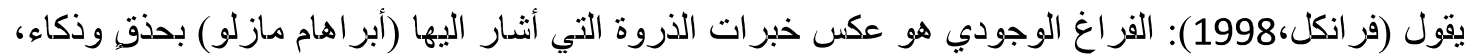

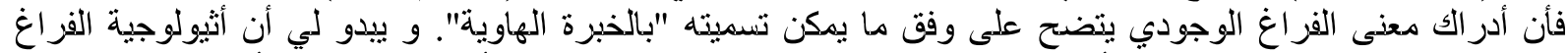

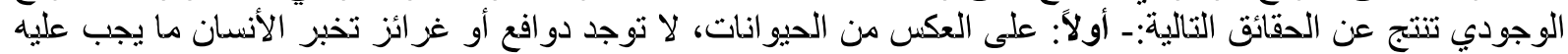

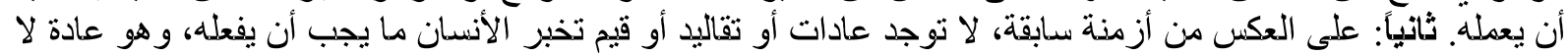

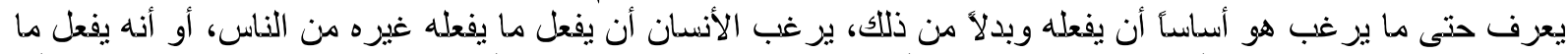

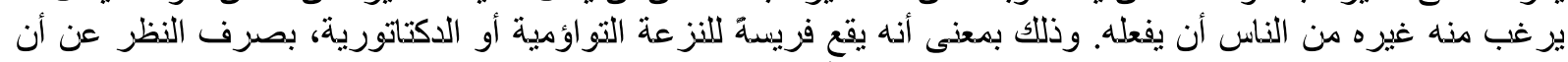

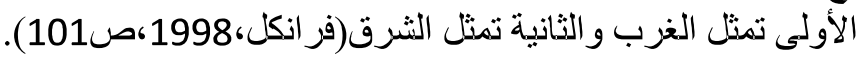

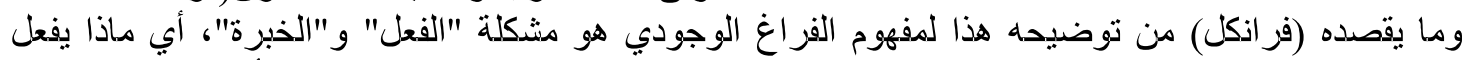

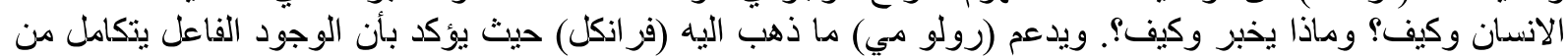

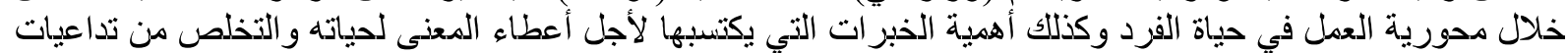

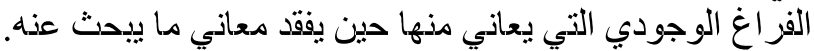

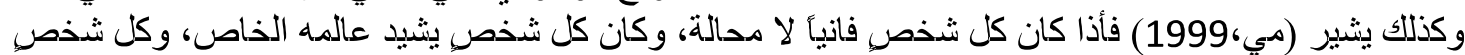

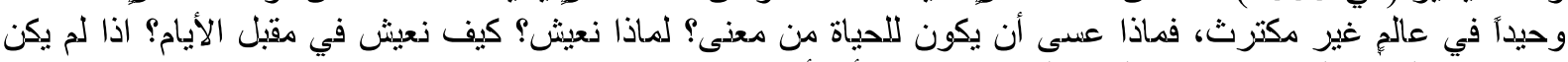

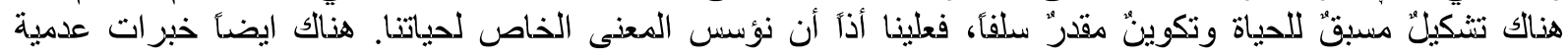

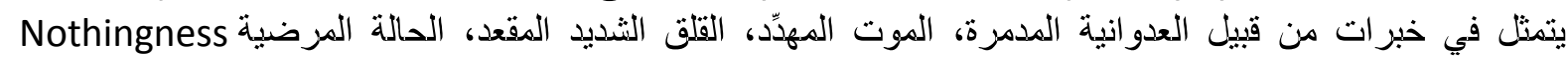

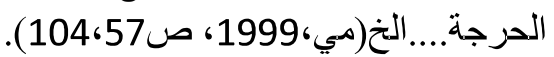

الجذور الفلسفية للفزاغ الوجودي

ومن الفلاسفة الذين أتخذت آر اءهم ومذظور اتهم بثأن وجود الانسان ومعاناته هم (سورين كيركيغارد وفردريك وديك

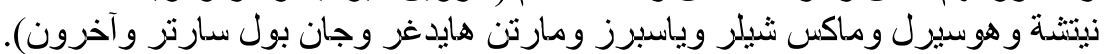

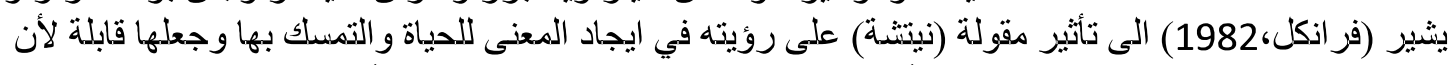
(who has a why to live

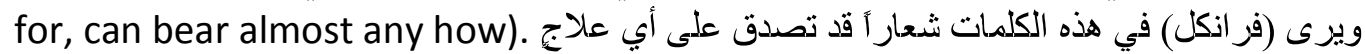

)نفسيFrankl,1992,P:109.(

ويثير (مارتن هايدجر) الى التفسير اليومي للنفس الذي يثير الى نزعة الفرد الى فهم نفسه أنطلاقأ من العالم الذي مثاي

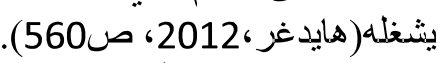

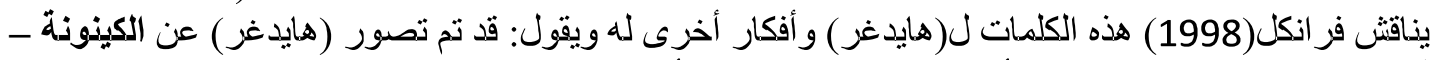

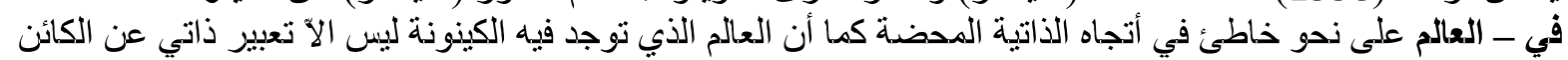

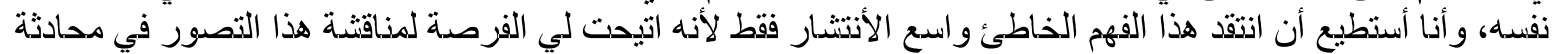

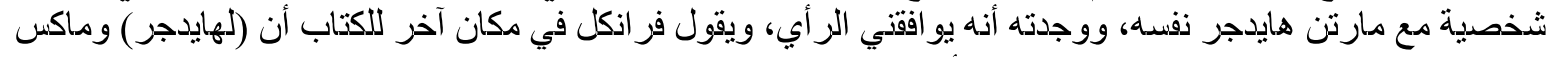

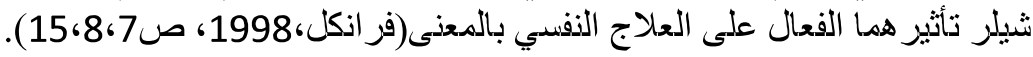


ويذكر (رولو ماي) في الكثير من مؤلفاته وبأهتمام كبير آر اء الفيلسوف الدانماركي (سورين كيركيغارد)

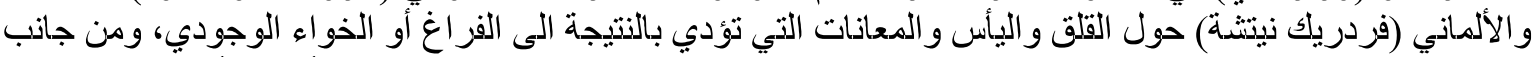

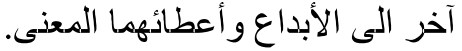

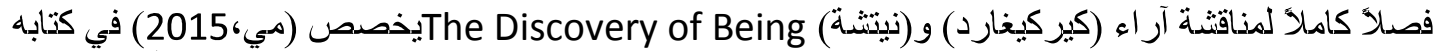

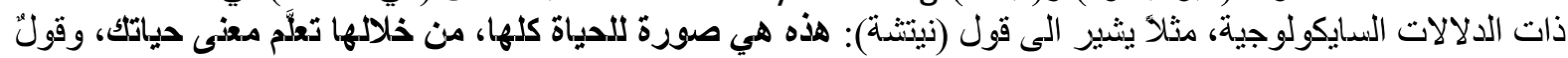

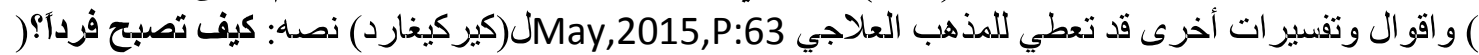

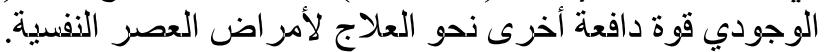

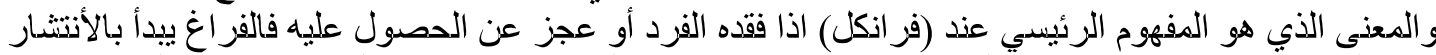

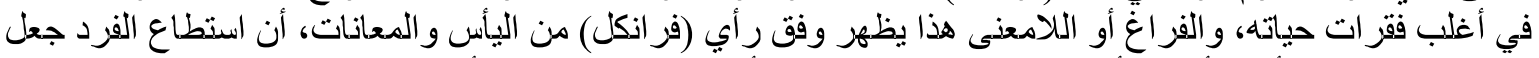

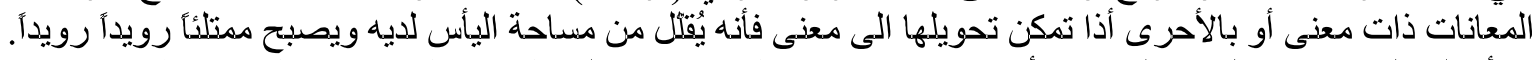

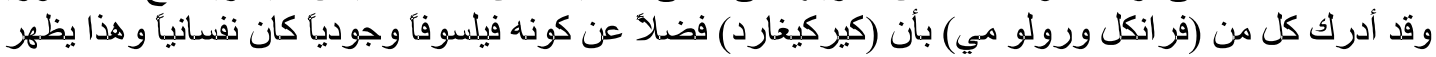

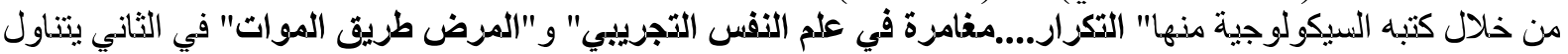

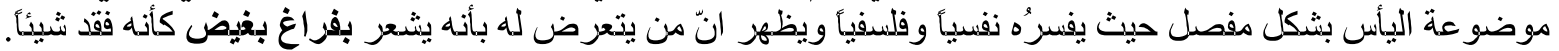

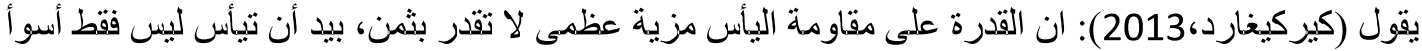

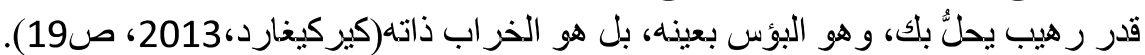

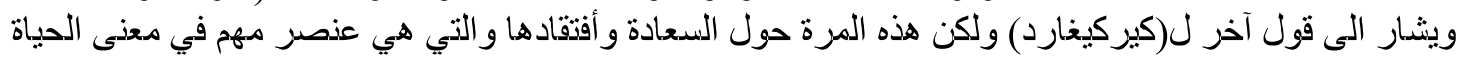

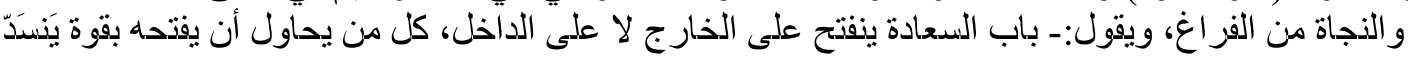

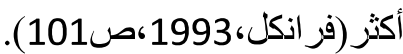

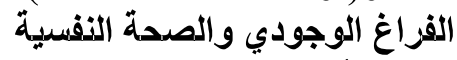

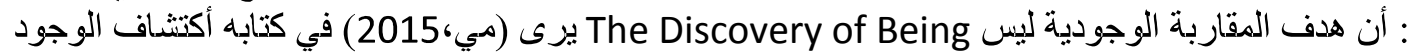

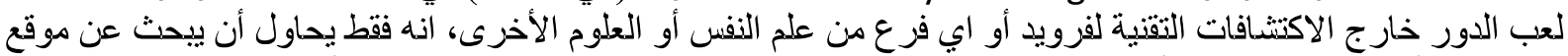

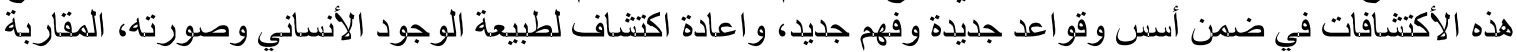

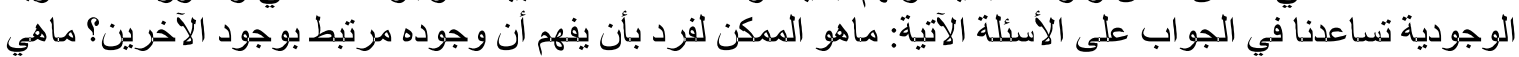

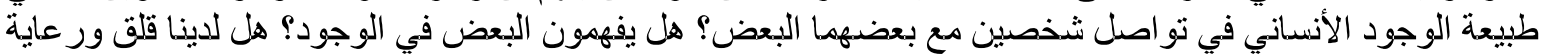

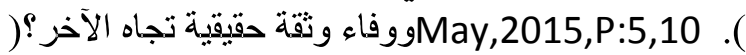

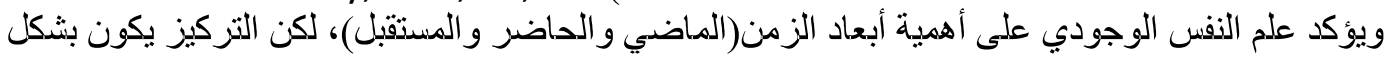

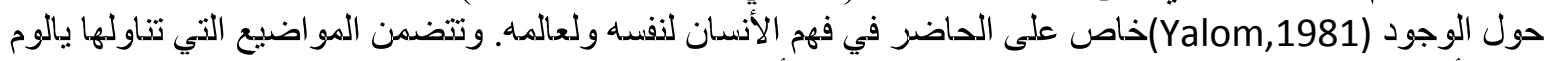

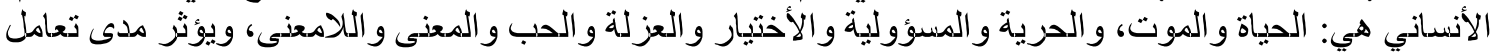

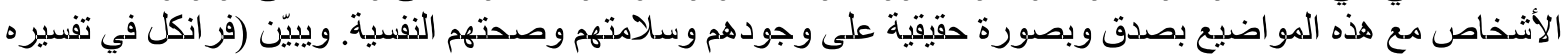

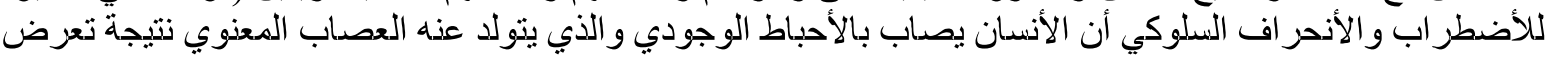

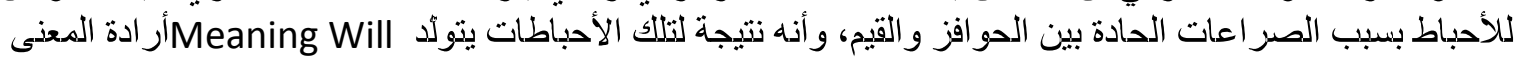

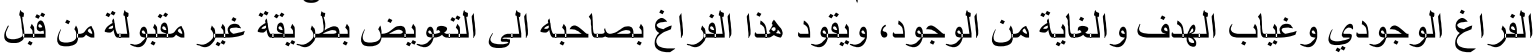

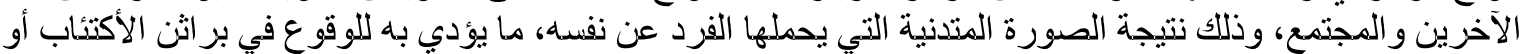

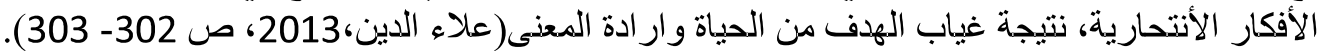

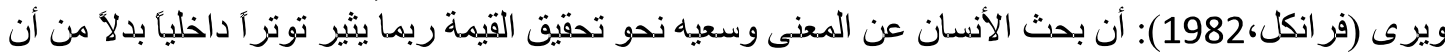

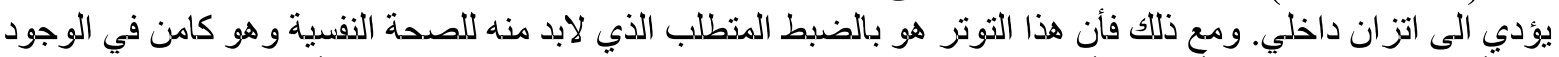

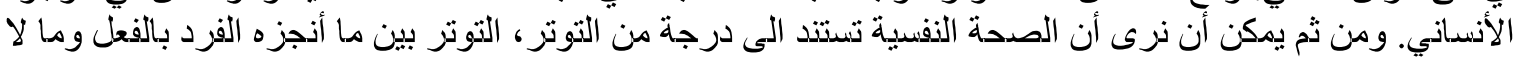

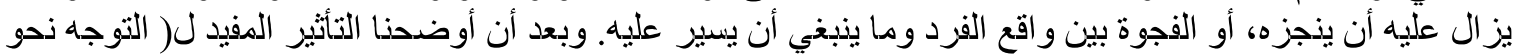

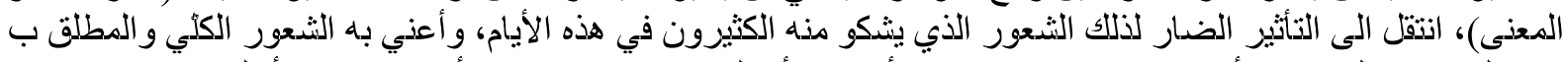

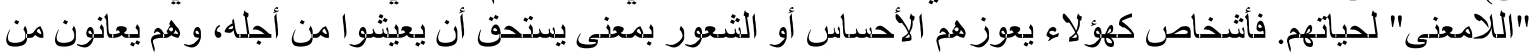

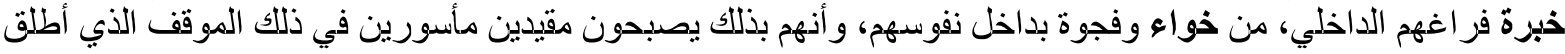

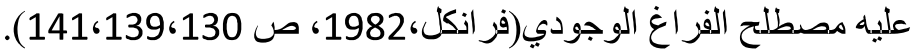

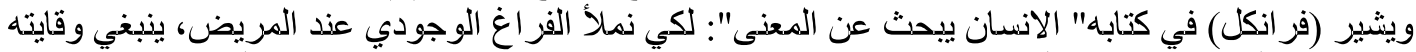

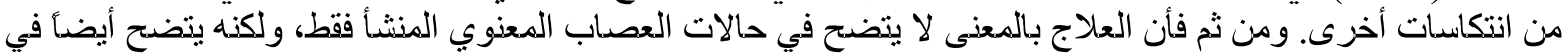

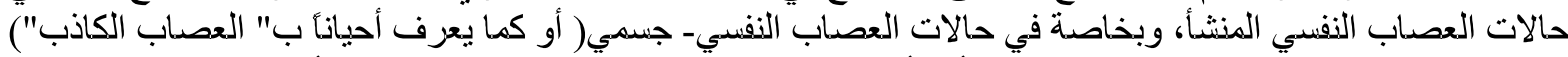

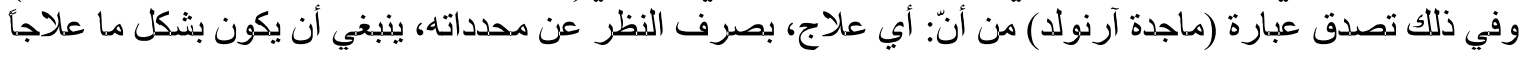

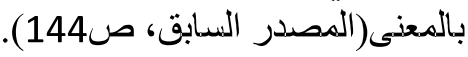


وفي در اسة حول الفراغ الوجودي لدى مرضى سرطان الثدي للخيلاني(2013) تبين بأن المتوسط الحسابي

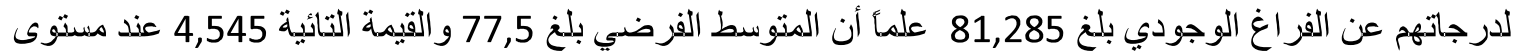

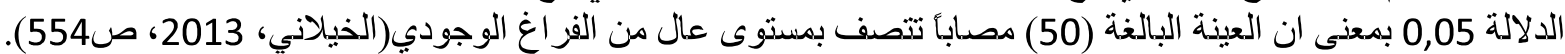

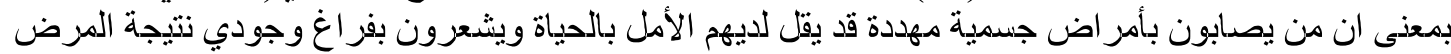

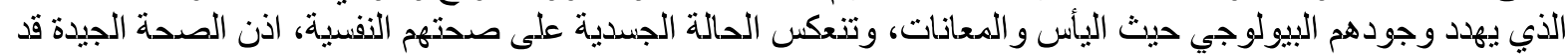

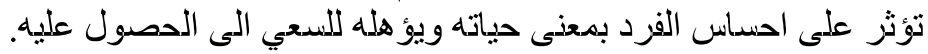

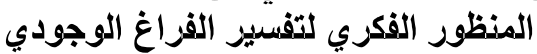

يتذاول الباحثان هنا أهم مذظورين فكريين للفراغ الوجودي و هما منظور (فر انكل) و(مي) وكالآتي:

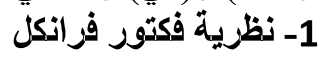

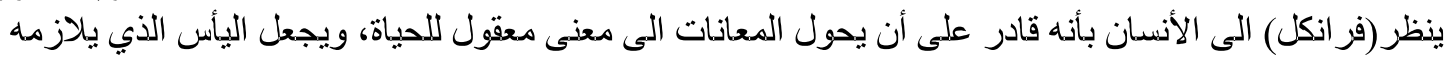

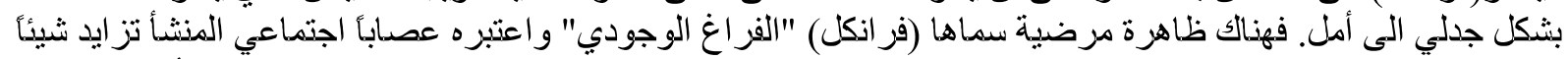

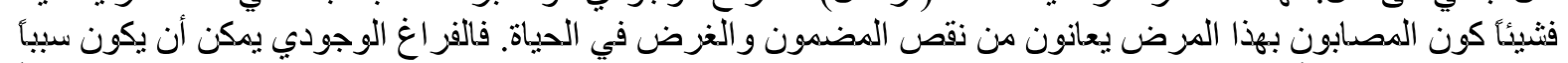

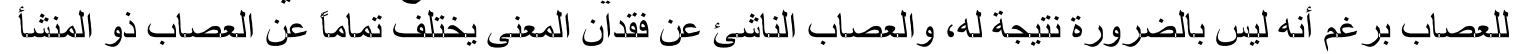

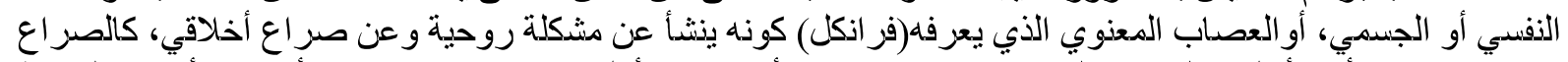

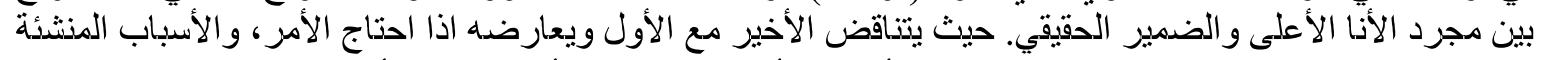

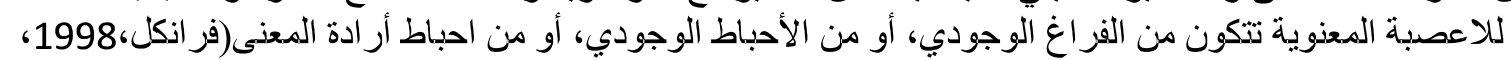

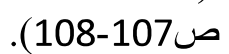

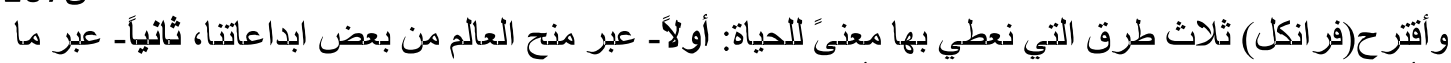

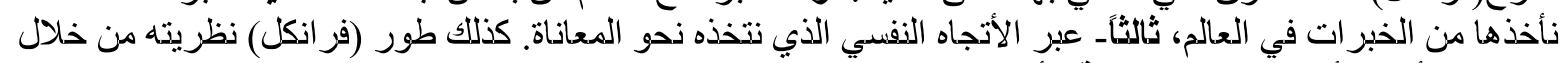

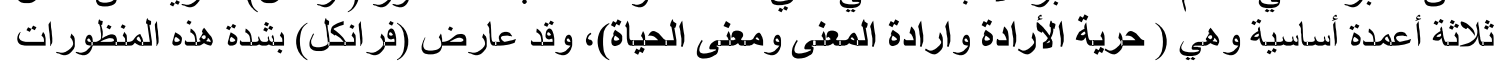

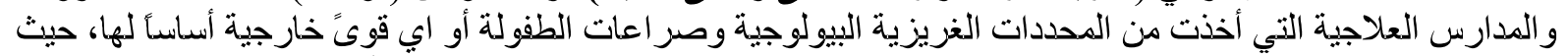

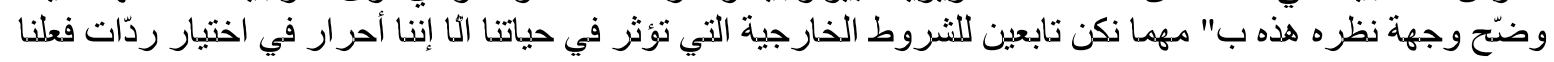
لهذه الثروط" Schultz,1977,P:108-109.(

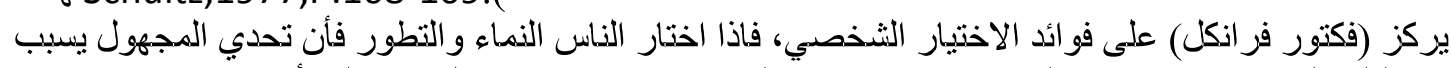

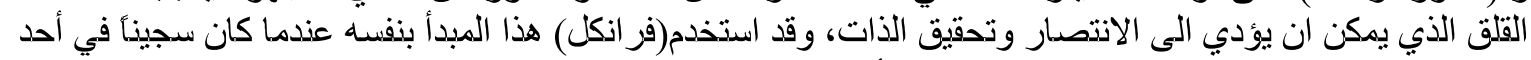

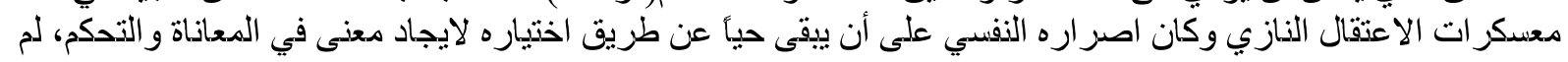

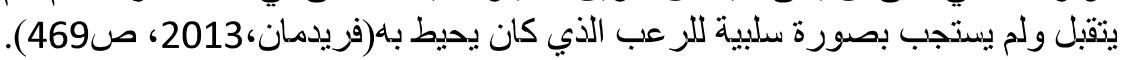

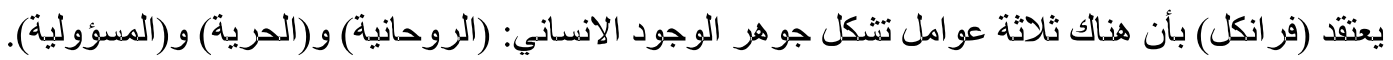

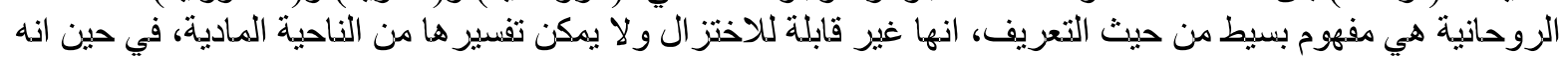

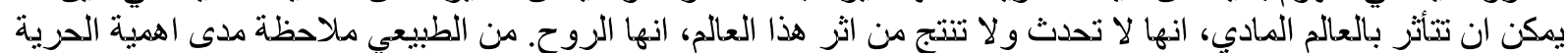

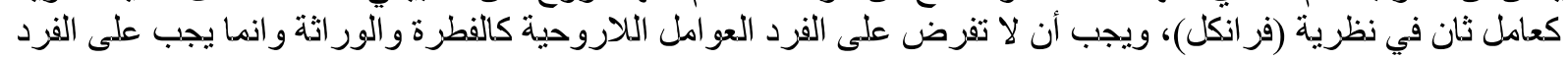

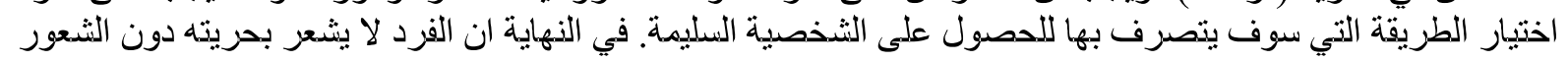

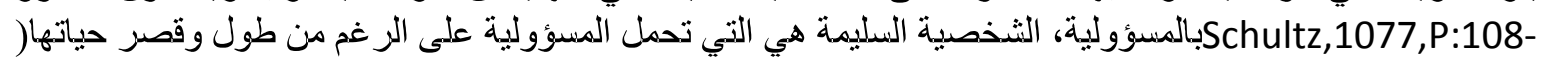
110. (

\section{Rollo May(1909-1994)}

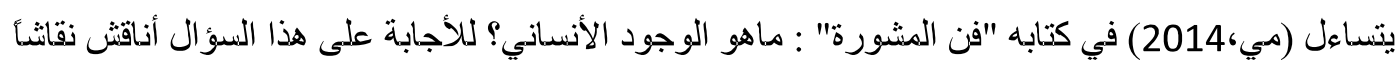

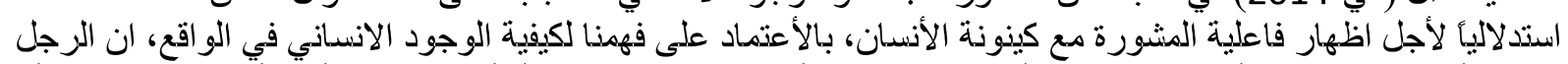

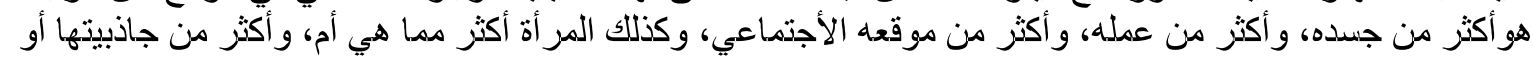

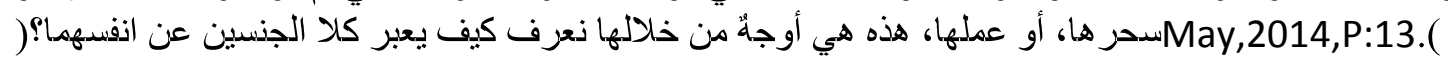

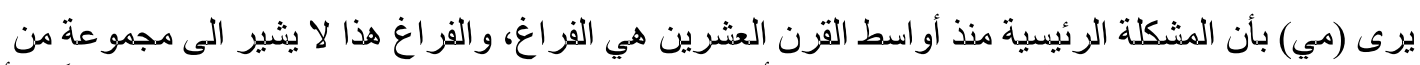

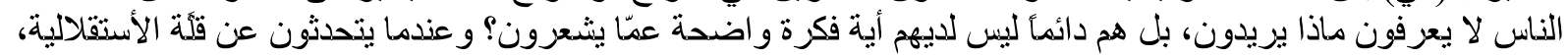

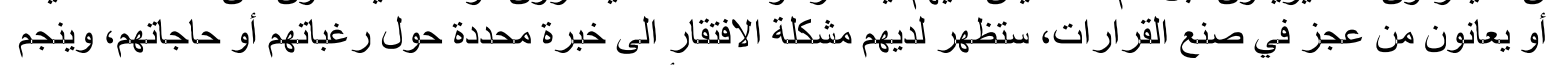

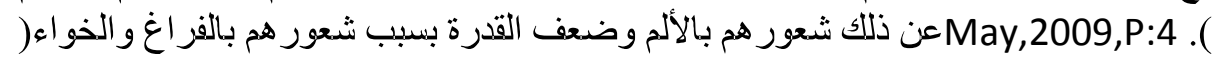

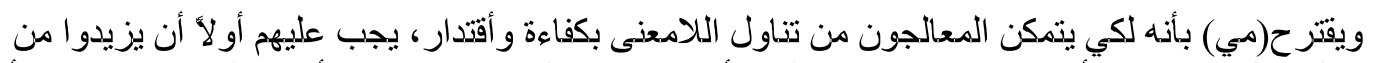

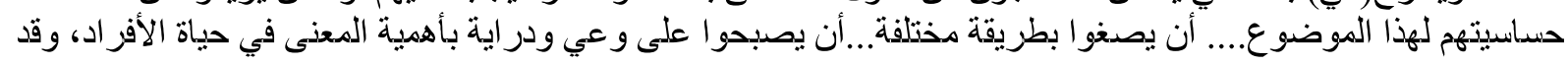




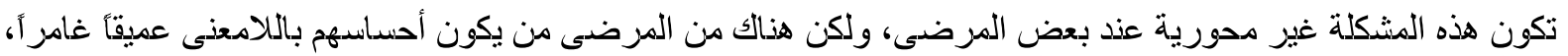

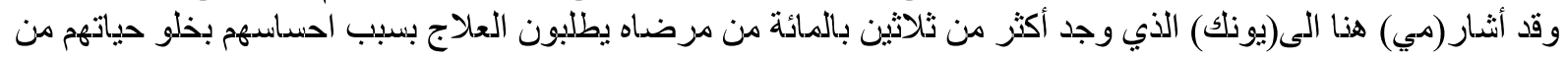

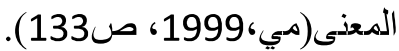

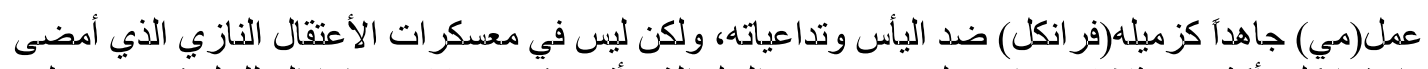

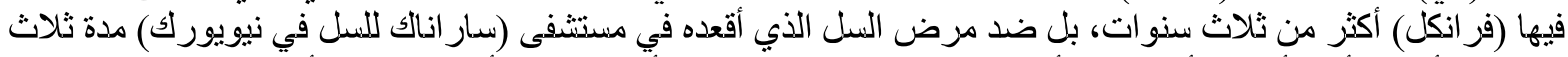

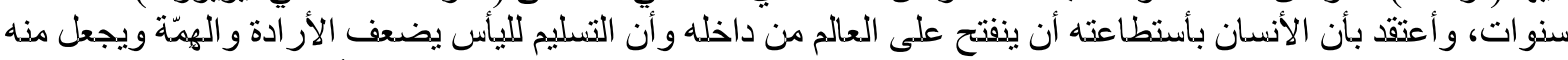

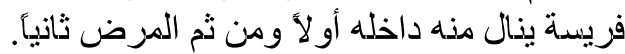

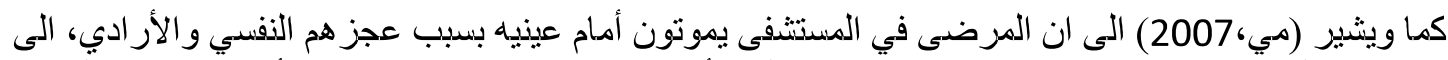

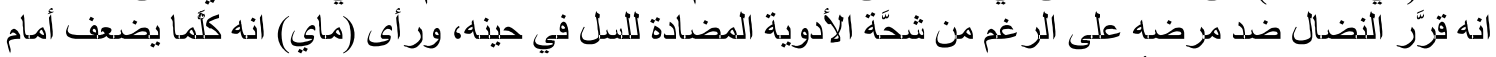

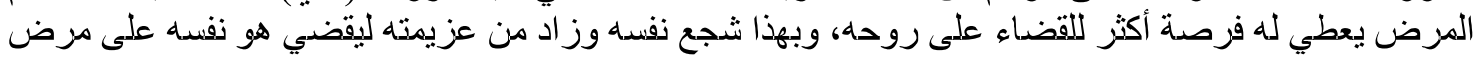

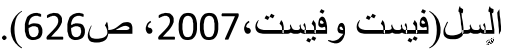

\section{الدراسات السابقة}

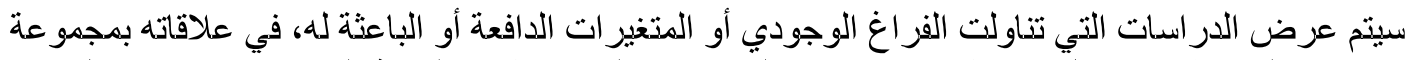

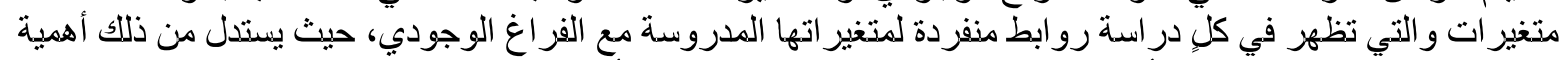

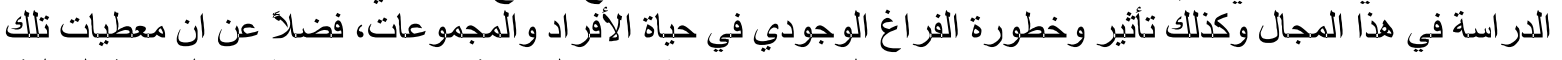
الدر اسات ستوظف في في المقارنة بيذها وبين معطيات الدر استة فئ الحالية.

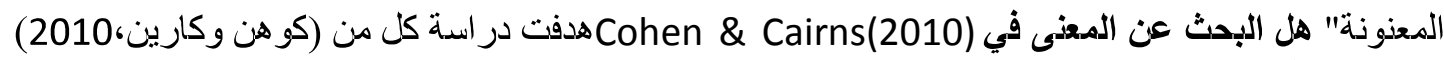

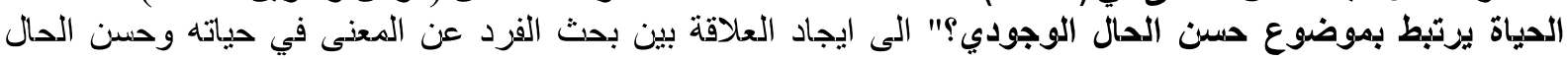

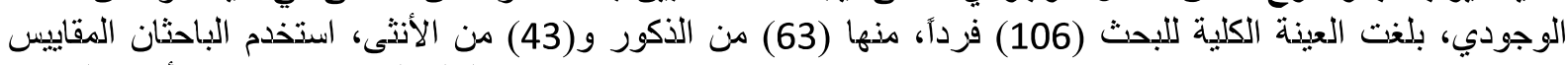
التالية لقياس استجو ابات أفر اد العينة:-

مقياس المعنى والباحث عن المعنى)، عدد فقزات المقياس هو 10.

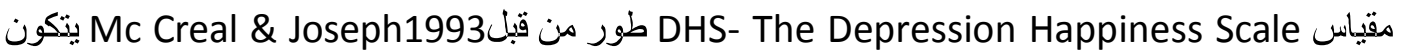
من 25 فقرة، الفقزات السلبية 13 و الايجابية 12.

توصلت الدر اسة الى النتائج التالية:

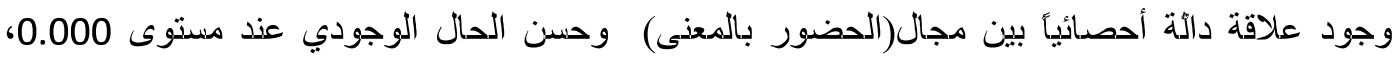
وكذلك مجال (الباحث عن المعنى) في مقياس البحث عن المعنى المعنى مع حسن الحال الوجودي عند الوند مستوى

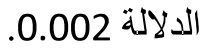
عدم وجود دلالة أحصائية لتفاعل العو امل من(الحضور و الباحث عن المعنى و الكآبة/السعادة). لدى طلبة جامعة (A,B)و هدفت (الو ائلي،2012) "في در استها "المعذى في الحياة وعلاقته بذمط الثخصية

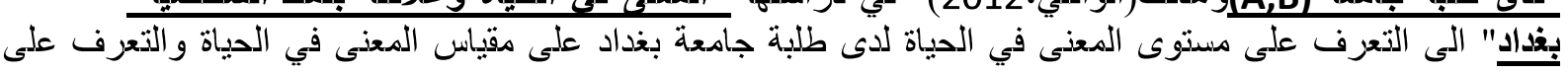

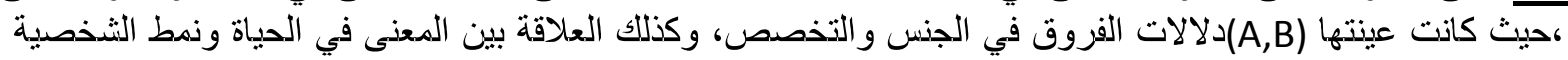
(400) فرداً من الذكور و الأناث.

وقد أظهرت النتائج ما يأتي:

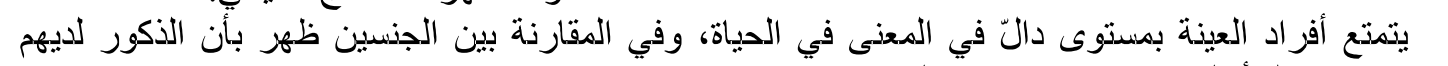

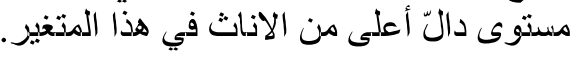

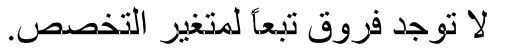


ملاحظة من الجدير الأشارة اليها : أثنارت الباحثة في مشكلة در استها بأن مفهوم فقدان المعنى هي الفراغ الوجي بعينه.

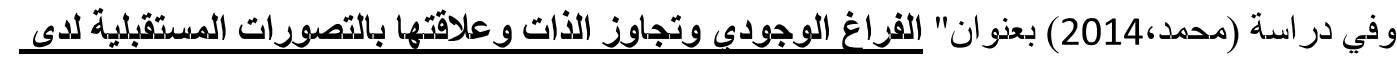

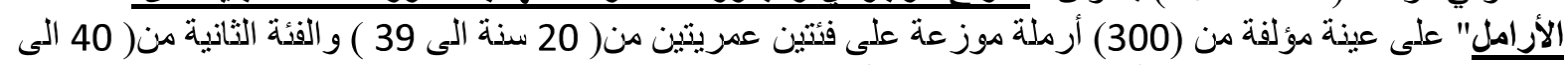

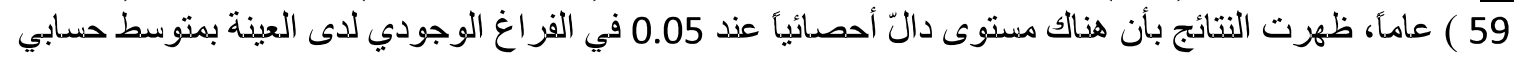

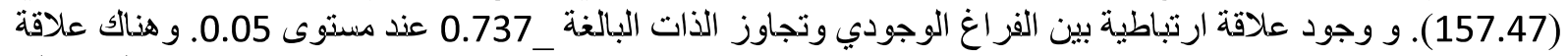

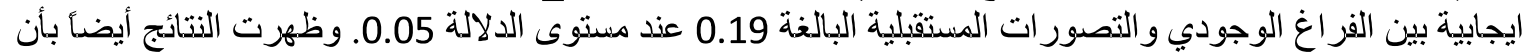

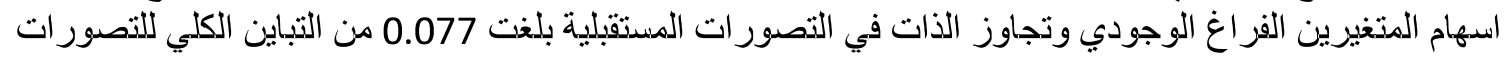
المستقبلية.

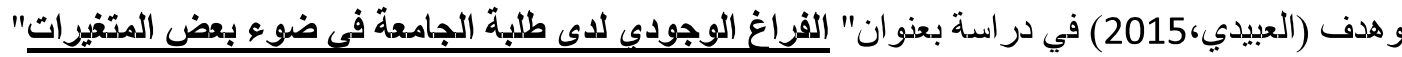

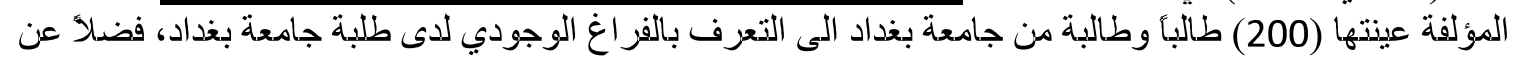

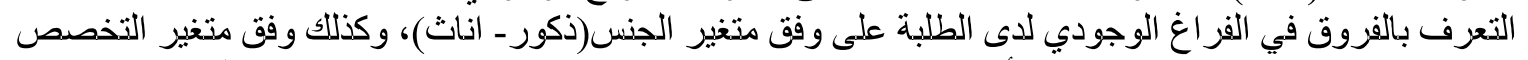

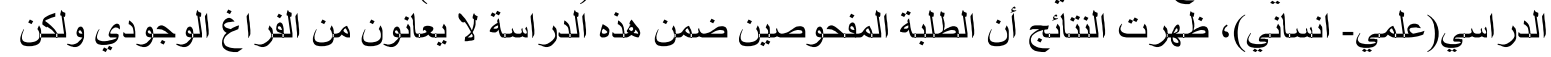

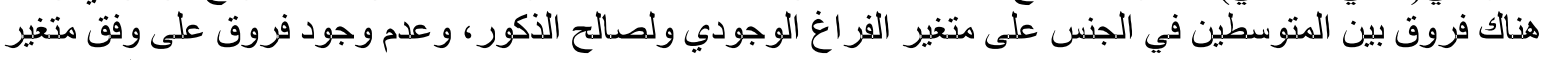

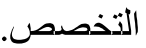

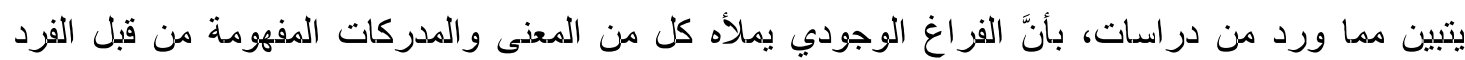

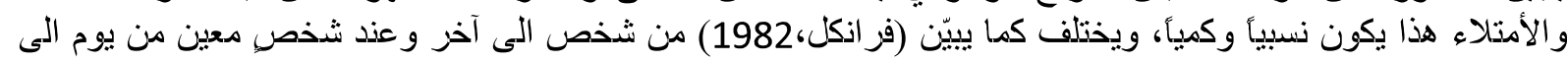

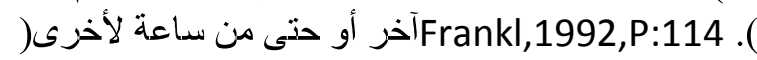

\section{مذهجية واجزاعات البحث}

سيتم عرض الاجر اءات المتبعة في البحث الحالي من حيث تحديد مجتمع البحث و وعيتته و الأدوات المستخدمة بعد

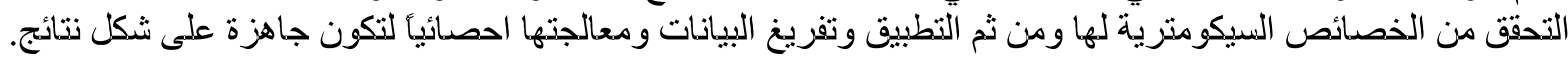

\section{مجتمع البحث}

يثتثمل مجتمع البحث على كل المنتمين الى أتحاد أدباء الكورد في فروع إقلى إليم كوردستان العز اقأ(أربيل

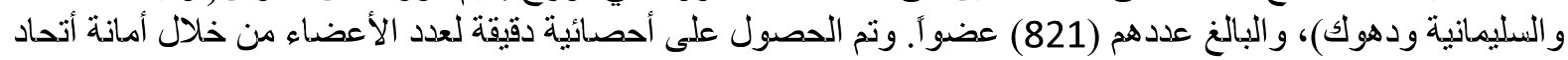

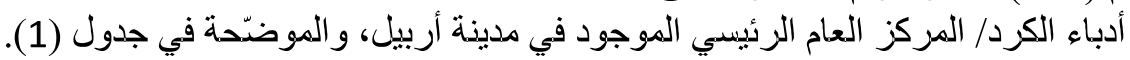

\section{جدول(1)}

المجتمع الأصلي

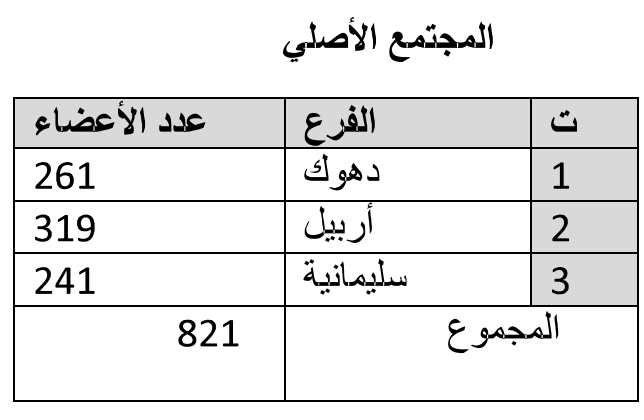

\section{عينة البحث}

بلغت عيذة البحث (159) فزداً من أدباء المحافظات الثثلاث للاقليم، وكانوا جميعاً من الذكور حيث تعذر إختيار

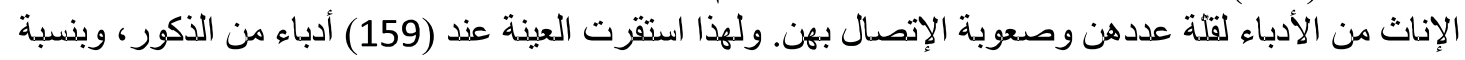

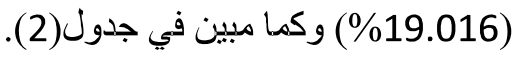


جدول) (2)

عينة البحث

\begin{tabular}{|c|c|c|c|c|}
\hline الذسبة المأخوذة & العينة المأخوذة & عدد الأعضاء & الفزع & $ت$ \\
\hline$\% 10.7279$ & 28 & 261 & دهوك & 1 \\
\hline$\% 24.7648$ & 79 & 319 & أربيل & 2 \\
\hline$\% 21.5767$ & 52 & 241 & السليمانية & 3 \\
\hline$\% 19.016$ & 159 & 821 & المجموع & \\
\hline
\end{tabular}

\section{أداة البحث}

تم إعداد أداة للفز اغ الوجودي وذلك من خلال الأدبيات النفسية والدقاييس الجاهزة وكذلك أعدّت أسئلة مفتوحة

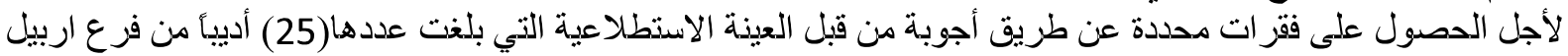

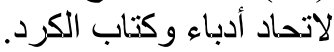

وقد بلغ عدد فقرات المقياس المُعَدّ (37) فقرة من بيذها فقر ات سلبية وأخرى أيجابية، مع مر اعاة الأسس السيكومترية في صياغة مراعة الفقزات مثل:-

أـ أن تكون الفقرة قابلة لتفسير واحد.

بـ عدم أستعمال الفقزات التي يحتمل أن يجيب عنها الجميع نفس الأجابة لكي لا تنعدم فرصة المقارنة.

ج- أن تقيس الفقرة الجانب الثعوري من الذات أو السلوك.

دـ تجنب أستعمال نفي النفي لأن ذلك من شأنه أن يربك المستجيب.

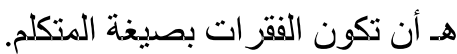

و عذد مر اجعة الفقزات وتمديصها تكونت الصيغة الأولية للمقياس.

الصدق الظاهزي لمقياس الفزاغ الوجودي

وُزّع المقياس على (11) خبير ا من المختصين في علم النفس، وبعد الإتفاق على صلاحية فقرات المقات المقياس استبقي

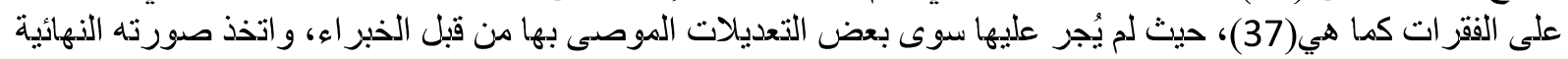

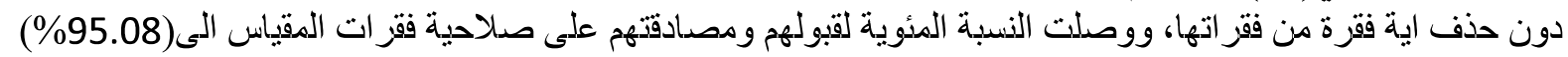
وبهذا تم التحقق من صدق المقياس.

\section{ثبات الأداة}

بعد أن تم التحقق من صدلاحية فقزات المقياس(الفراغ الوجودي)، تم تطبيق اجز اءات الثيات الثبات بطريقة اعادة

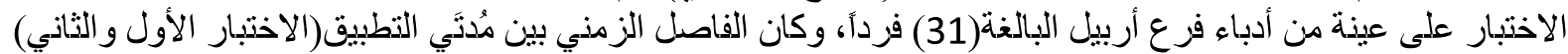

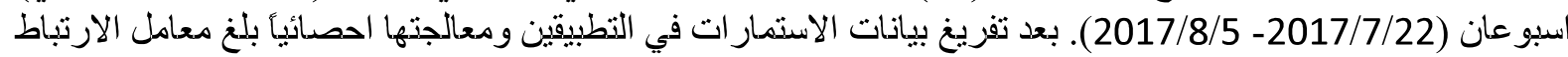

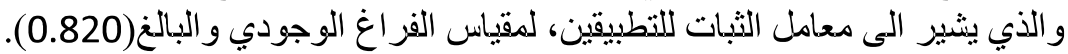


القوة التمييزية لفقرات مقياس الفزاغ الوجودي

Contrasted

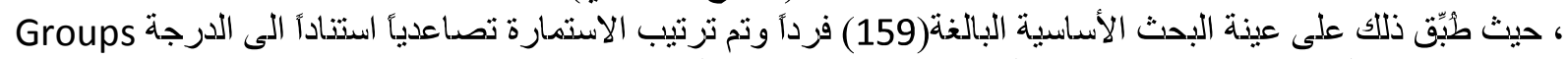

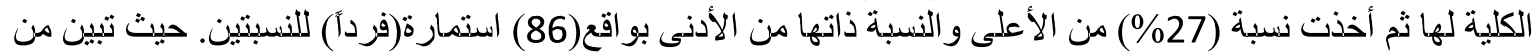

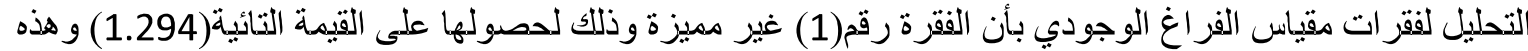

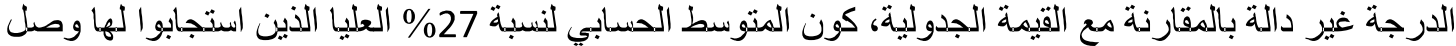

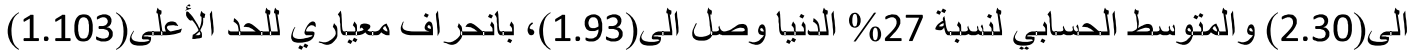

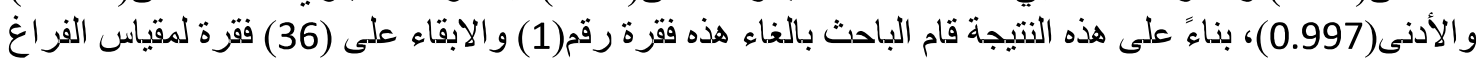

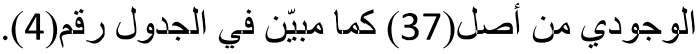

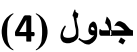

المتوسطات والاندرافات المعيارية والقيم التائية لمجموعة(27\%) العليا ومجموعة(27\%) الدنيا لفقرات مقياس

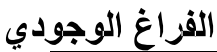

\begin{tabular}{|c|c|c|c|c|c|}
\hline \multirow[t]{2}{*}{ القيمة التائية } & \multicolumn{2}{|c|}{ المجموعة الدنيا } & \multicolumn{2}{|c|}{ المجموعة العليا } & \multirow[t]{2}{*}{ رقم الفقزة } \\
\hline & الآدياري & الوسط الحسابي & الالدعياري & الوسط الحسابي & \\
\hline 1.294 & 0.997 & 1.93 & 1.103 & 2.30 & 1 \\
\hline$* 2.884$ & 0.832 & 1.67 & 1.368 & 2.56 & 2 \\
\hline$* 6.286$ & 0.447 & 1.26 & 1.074 & 2.67 & 3 \\
\hline$* 4.749$ & 0.847 & 1.44 & 1.188 & 2.78 & 4 \\
\hline$* 3.498$ & 1.188 & 1.89 & 1.224 & 3.04 & 5 \\
\hline$* 6.795$ & 0.396 & 1.19 & 1.330 & 3.00 & 6 \\
\hline$* 4.429$ & 1.155 & 1.56 & 1.357 & 3.07 & 7 \\
\hline$* 3.882$ & 0.267 & 1.07 & 1.160 & 1.96 & 8 \\
\hline$* 6.921$ & 0.526 & 1.26 & 1.436 & 3.30 & 9 \\
\hline$* 6.965$ & 0.424 & 1.11 & 1.315 & 2.96 & 10 \\
\hline$* 5.157$ & 1.050 & 1.44 & 1.311 & 3.11 & 11 \\
\hline$* 4.702$ & 0.884 & 1.37 & 1.379 & 2.85 & 12 \\
\hline$* 4.048$ & 0.917 & 1.93 & 1.331 & 3.19 & 13 \\
\hline$* 4.943$ & 1.043 & 1.63 & 1.551 & 3.41 & 14 \\
\hline$* 4.007$ & 1.292 & 1.85 & 1.289 & 3.26 & 15 \\
\hline$* 7.299$ & 0.267 & 1.07 & 1.210 & 2.81 & 16 \\
\hline$* 4.246$ & 1.145 & 1.81 & 1.347 & 3.26 & 17 \\
\hline$* 5.902$ & 0.192 & 1.04 & 1.586 & 2.85 & 18 \\
\hline$* 4.182$ & 0.801 & 1.22 & 1.068 & 2.30 & 19 \\
\hline$* 3.772$ & 0.892 & 1.78 & 1.050 & 2.78 & 20 \\
\hline$* 8.500$ & 0.320 & 1.11 & 1.109 & 3.00 & 21 \\
\hline$* 7.322$ & 0.656 & 1.26 & 1.259 & 3.26 & 22 \\
\hline$* 4.899$ & 0.555 & 1.33 & 1.301 & 2.67 & 23 \\
\hline$* 5.669$ & 1.087 & 1.52 & 1.121 & 3.22 & 24 \\
\hline$* 5.898$ & 0.338 & 1.04 & 1.023 & 2.26 & 25 \\
\hline$* 2.711$ & 1.477 & 2.52 & 1.221 & 3.52 & 26 \\
\hline$* 5.806$ & 0.700 & 1.48 & 1.126 & 2.96 & 27 \\
\hline$* 5.161$ & 0.974 & 1.78 & 1.130 & 3.26 & 28 \\
\hline$* 6.765$ & 0.698 & 1.56 & 1.039 & 3.19 & 29 \\
\hline$* 8.530$ & 0.688 & 1.37 & 1.006 & 3.37 & 30 \\
\hline
\end{tabular}

International Journal of Kurdish Studies Vol.5/1 ( January 2019) 


\begin{tabular}{|l|l|l|l|l|l|}
\hline$* 2.592$ & 0.892 & 1.89 & 0.893 & 2.52 & 31 \\
\hline$* 6.022$ & 0.580 & 1.48 & 1.281 & 3.11 & 32 \\
\hline$* 4.869$ & 0.742 & 1.63 & 1.121 & 2.89 & 33 \\
\hline$* 3.555$ & 0.320 & 1.11 & 1.315 & 2.04 & 34 \\
\hline$* 5.028$ & 0.456 & 1.15 & 1.421 & 2.59 & 35 \\
\hline$* 2.691$ & 0.893 & 1.48 & 1.295 & 2.30 & 36 \\
\hline$* 2.906$ & 0.844 & 1.41 & 1.188 & 2.22 & 37 \\
\hline
\end{tabular}

دالةّة عند مسنتوى أقلّ من 0.05

التطبيق النهائي

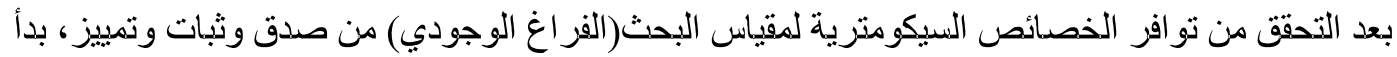

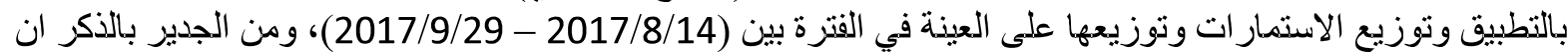

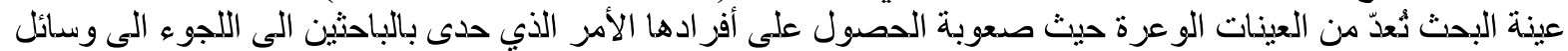

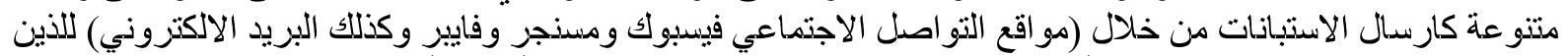

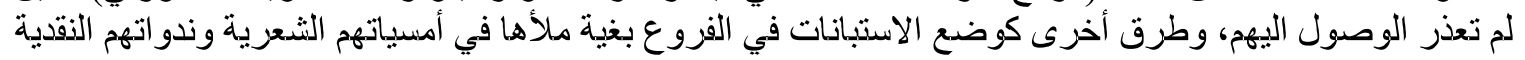

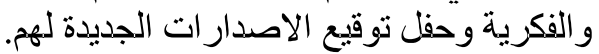

\section{عزض النتائج ومناقشتها}

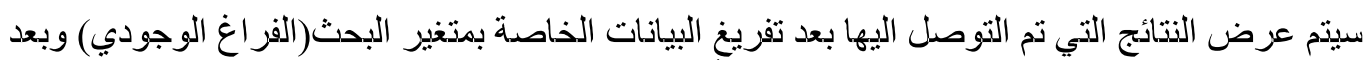

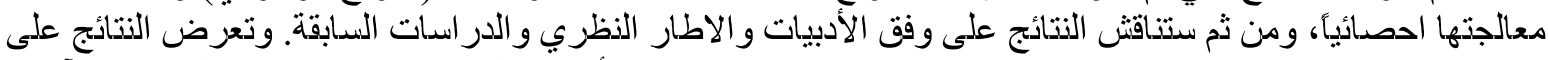
وفق الأهداف المحددة مسبقاً في هذا البحث وكرات والآتي:

1- الهدف الأول: مستويات الفزاغ الوجودي لدى العينة ككل، والتعزف على دلالاتها بحسب الأوساط الفرضية:

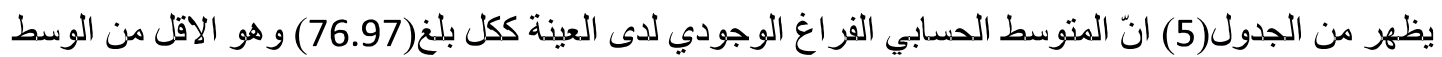

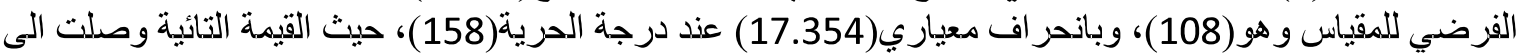

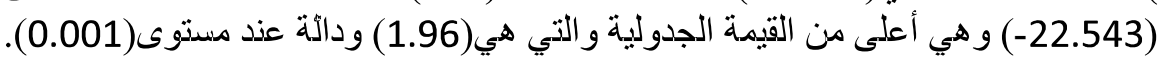

جدول (5)

قياس مستويات (الفزاغ الوجودي) ودلالاتها

\begin{tabular}{|c|c|c|c|c|c|c|c|c|c|}
\hline مستوى الدلاية & الجدولية & التائية & الدرية & الالمعياري & الدسابي & الفزضي الوسط & العينة & المتغيز & ت \\
\hline 0.001 & 1.96 & -22.543 & 158 & 17.354 & 76.97 & 108 & 159 & الفز اغ الوجودي & 1 \\
\hline
\end{tabular}

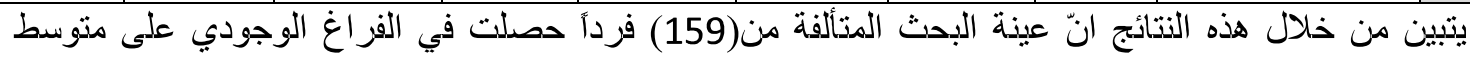

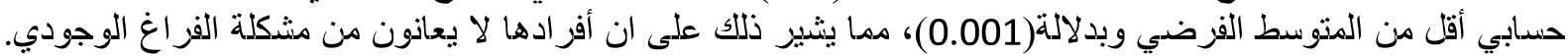

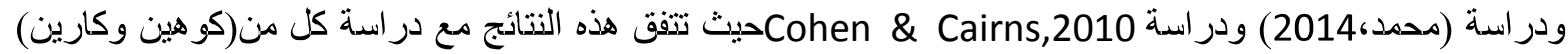

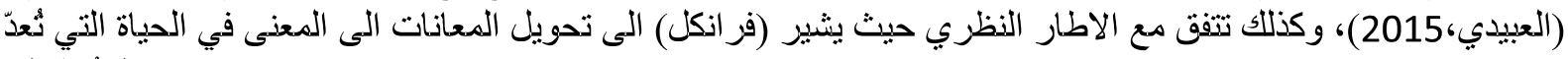
خبرة ايجابية مُدركّة.

ومن الجدير بالذكر هناك بعض العوامل غير الظاهزة قد تدخل كمتغير ات دخيلة في التأثير على النتائج حيث البيئة التئة

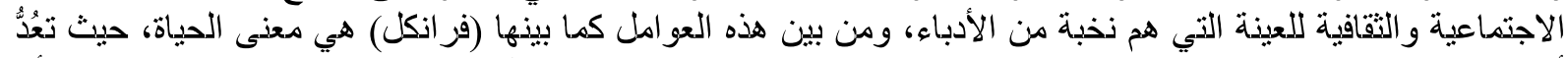

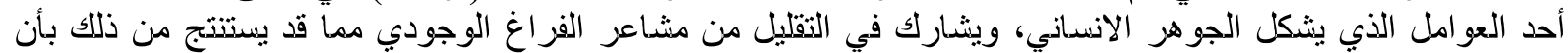

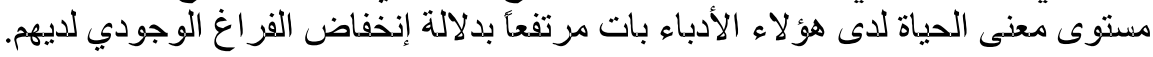

2- قياس مستويات الفزاغ الوجودي بحسب العمز والمكان

International Journal of Kurdish Studies Vol.5/1 ( January 2019) 


\section{أ- المكان(الفروع):}

من خلال البيانات المعزوضة الخاصة بهذا الهدف في الجدول(6) أظهزت النتائج ما يلي:

- بلغ المتوسط الحسابي للفز اغ الوجودي لأفز اد العيذة المنتمين الى فرع دهوك لاتحاد الأدباء وعددهم (28) فرداً

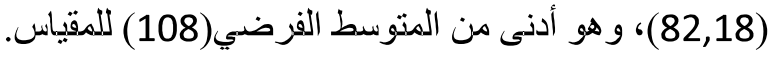

- بالنسبة لأفراد العيذة المنتمين الى فرع أربيل لاتحاد الأدباء والبالغ عددهم(79)، بلغ المتوسط الحسابي للفراغ الوجودي

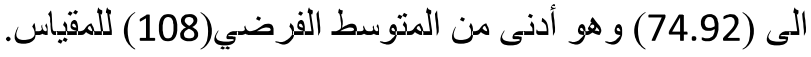

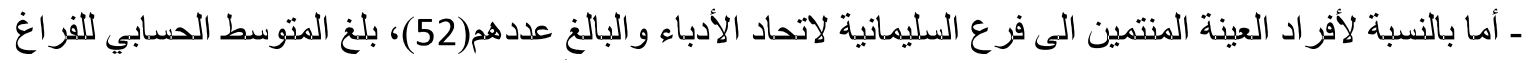

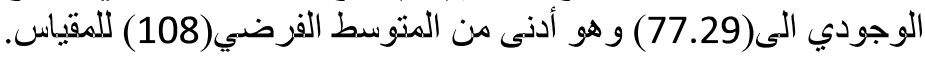

وقد أظهر تحليل التباين بأن الفروق بين المجموعات في(الفراغ الوجودي) ليست دائة حيث القيمة الفائية وصلت

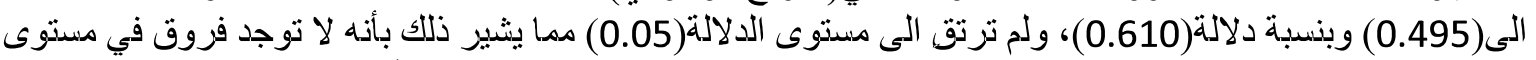

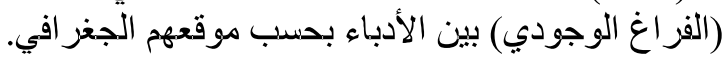

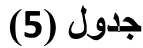

مستويات الفزاغ الوجودي بحسب المكان(فزوع الاتحاد)

\begin{tabular}{|c|c|c|c|c|c|c|c|c|c|c|c|}
\hline \multirow[t]{2}{*}{ النتيجة } & \multirow{2}{*}{ الدلالة } & \multirow{2}{*}{ القائية } & \multirow{2}{*}{ الفرضي المتوسط } & \multicolumn{6}{|c|}{ المتوسطات الحسابية بحسب المكان وعدد أفزاده } & \multirow[t]{2}{*}{ المتغيز } & \\
\hline & & & & $\dot{ن}$ & السليمانية & ن & أربيل & $\dot{ن}$ & دهوك & & \\
\hline بر دائة & 0.163 & 1.838 & 108 & 52 & 77.29 & 79 & 74.92 & 28 & 82.18 & الفراغ الوجودي & 1 \\
\hline
\end{tabular}

مستّى الدّلالة=0.05

بـ الفئات العمزية:

أظهرت النتائج المبيذة في الجدول(14) لقياس مستويات (الفزاغ الوجودي) بحسب الفئات العمرية الثلاثة(25-

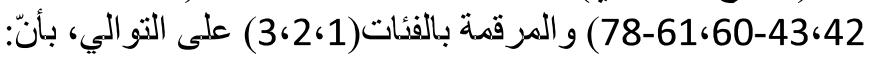

- عينة الفئة(25-42) و البالغة(27) فرداً وصل متوسطها الحسابي في الفزاغ الوجودي الى درجة(100.00)

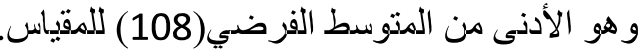

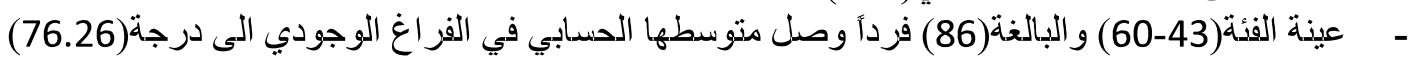

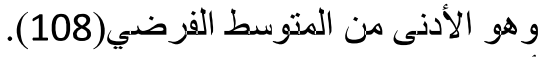

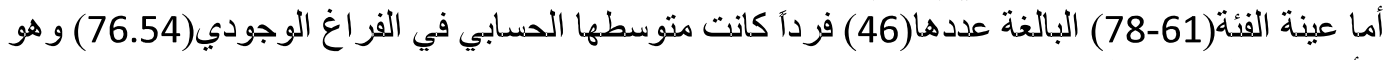

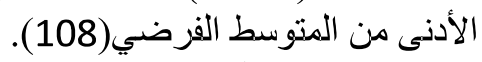

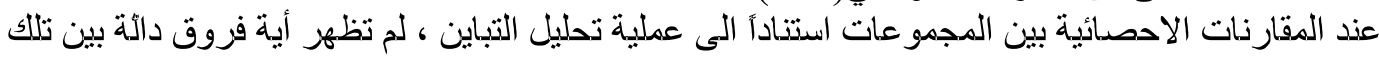

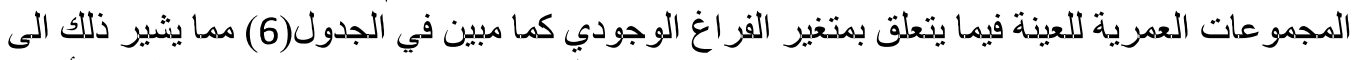

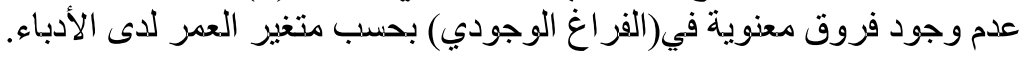

(6) (6دول)

مستويات الفراغ الوجودي بحسب العمر المقسم الى فئات عمرية

\begin{tabular}{|c|c|c|c|c|c|c|c|c|c|c|c|}
\hline \multirow[t]{2}{*}{ النتيجة } & \multirow[t]{2}{*}{ الدلالة } & \multirow[t]{2}{*}{ القائية } & \multirow{2}{*}{ الفرتوس ط الفرضي } & \multicolumn{6}{|c|}{ المتوسطات الحسابية للفئات العمزية وعداد أفراد } & \multirow[t]{2}{*}{ المتغيز } & \multirow[t]{2}{*}{ ت } \\
\hline & & & & ن & 3 & $\dot{ن}$ & 2 & $\dot{ن}$ & 1 & & \\
\hline 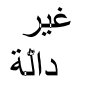 & 0.610 & 0.495 & 108 & 46 & 76.54 & 86 & 76.26 & 27 & 80.00 & الفزاغ الوجودي & 1 \\
\hline
\end{tabular}




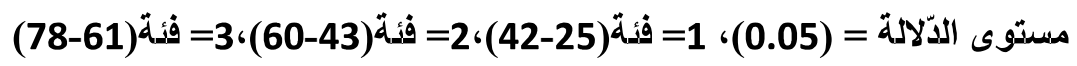

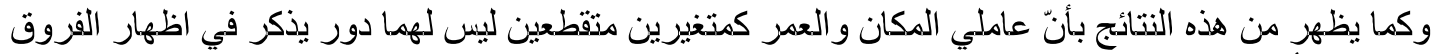

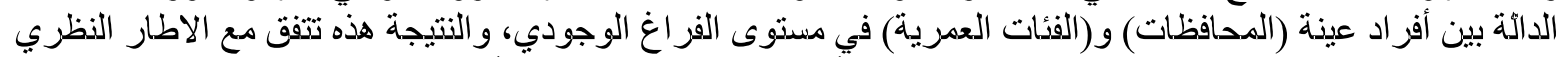

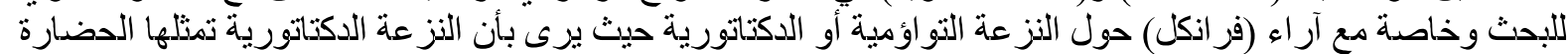

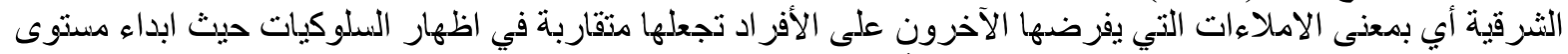

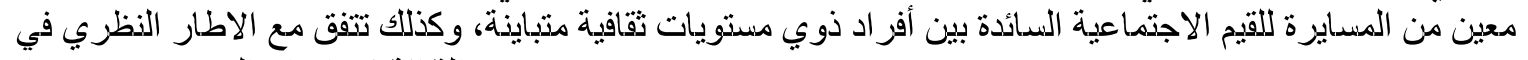

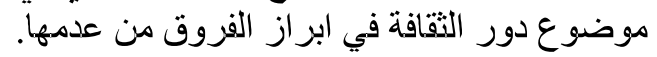

وان عدم ظهور الفزوق الدالة في مستويات الفراغ الوجودي للبحث الحالي بين عينات (المكان- الفزوع)

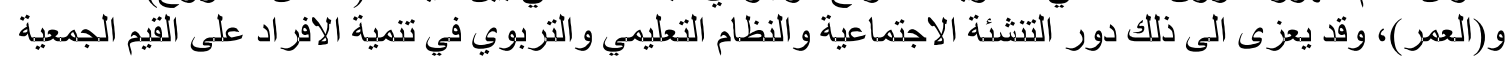

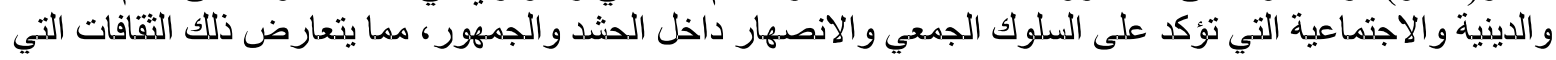

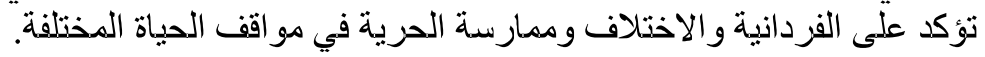

التوصيات والمقترحات

\section{التوصيات}

على وفق النتاج التي تم التوصل اليها، تقدم التوصيات الآتية الى الجهات المعنية:

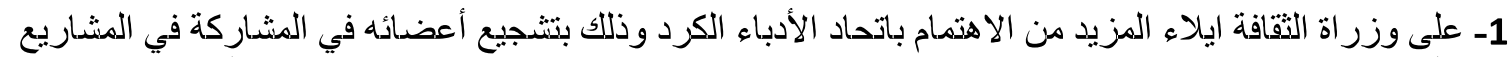

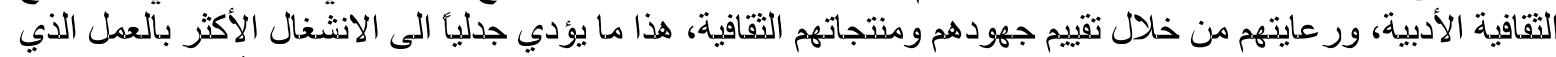

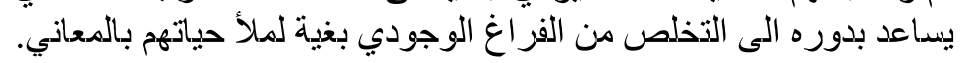

2- وكذلك على الوزارة نفسها ايجاد روابط نشطة للأدباء و افساح المجال لهم لتسهيل مهمتهم بالتو اصل مع العال التهالم الخارجي

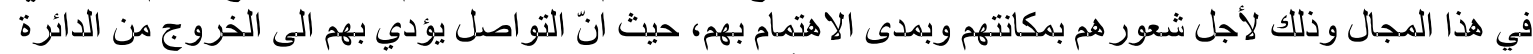

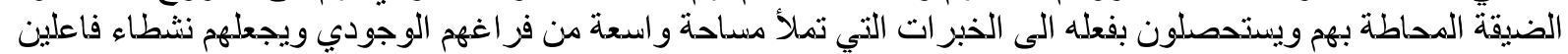

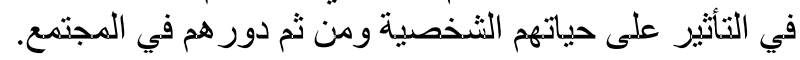

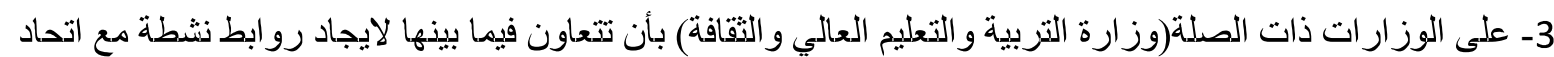

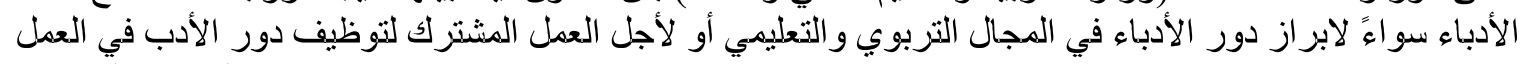
الثقافي و التربوي.

4- على وزارة الصحة القيام بنثاطات نوعية تبرز من خلالها دور الصحة الذفسية والعقلية في حياة الفرد وأن تبدأ وذلك الكالك

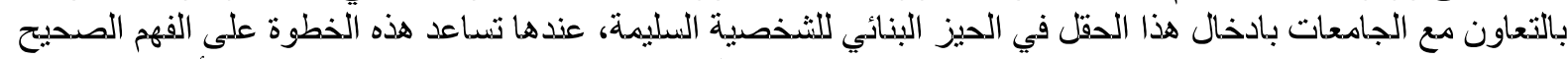

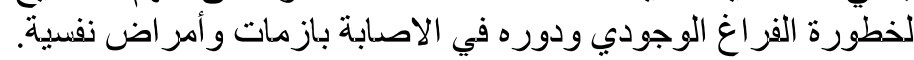

\section{المقتزحات}

تقدم المقترحات الآتية للباحثين مستقبلأ وكالآتي:

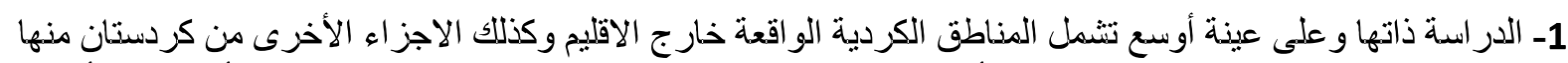

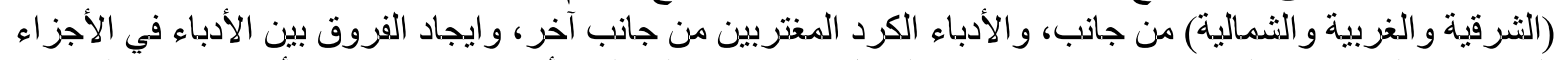

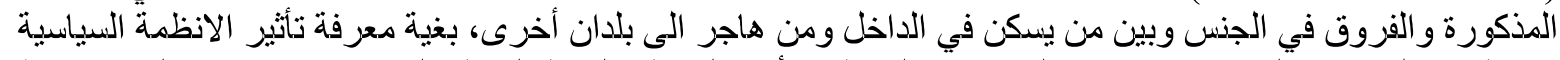

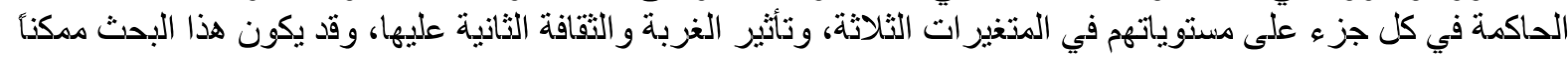

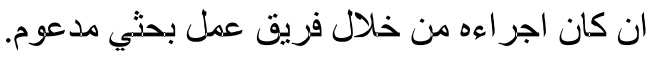




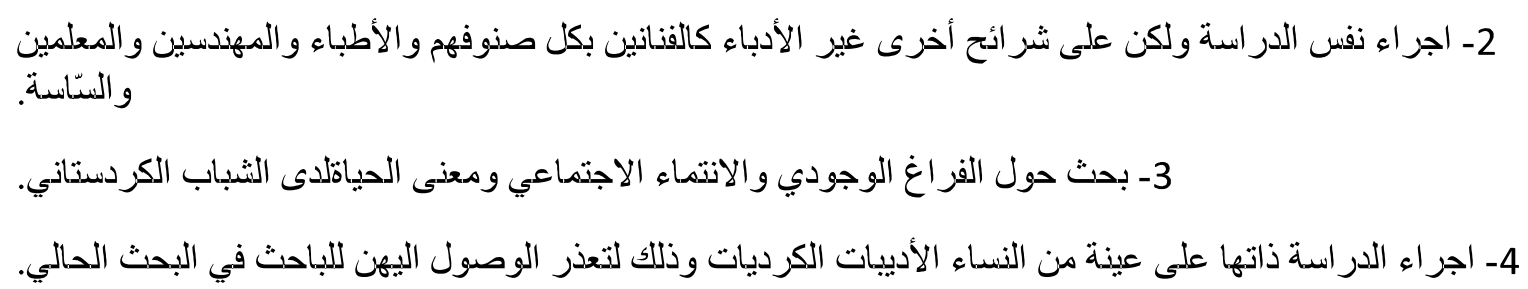

\section{References}

Adler, Alfred, (2009).The Meaning of Life, T: Adel Naguib Boshra, National Project of Translation, 2, Cairo.

Al-Khailani, Kamal Mohammed Sarhan, (2013). Emotional emptiness in women with breast cancer, Journal of Educational and Psychological Sciences - Iraq, No. 99.

Aladdin, Jihad Mahmoud, (2013). Theories of Psychology and Human Knowledge, Al Ahlia for Publishing and Distribution, 1, Amman.

Al-Obaidi, Afra Ibrahim Khalil, (2015). Theories of cognitive and human psychological counseling, University of Baghdad - Faculty of Education for Girls.

Al-Waeli, Jamila, (2012). The Meaning of Life and its Relationship to Personality Patterns (A, B) of Baghdad University Students, Journal of the Professor, No. 201, Girls College of Education, University of Baghdad.

Fist, Jest \& Fist, Crickey, (2007). Personality Theories, Translator: Yahya Seyyed Mohammadi, Nashr Ravan, Jab 3.

Frankel, Victor, (1982). Man cearch for meaning, T: d. Talaat Mansour, 1st Floor, Dar Al Qalam, Kuwait.

Frankel, Victor, (2014). The Will to meaning ... Foundations and applications of treatment in the sense, T: d. Ayman Fawzi, Zahraa Al Sharq House, Cairo.

Frankl, Viktor E., (1992). Mans Search for Meaning. An Introduction To Logotherapy,4th Edition, Beacon Press 25,Boston- Massachusetts.

Frankl, Factor, (1993). Physician and Ghost, translation of Farsi: d. Farrokh Seif Behzad, Dorsa Publishing House, Jab 3, Tehran.

Friedman, Howard S. \& Shastak, Miriam, (2013). Personal. Classical theories and modern research, T. Ahmed Ramo, Arab Organization for Translation, I 1, Beirut.

Heidegger, Martin, (2012). Being and Time, d. Fathi Al-Muskini, New United Book House, 1 st, Beirut. 
Karen,Cohen \& Cairns, David, (2010). Is Searching for Meaning in Life Associated With Reduced Subjective and Psychological Well- Being?, International Juornal of Existential Psychology \& Psychotherapy,V 3,n 1,January.

Kirkgord, Surin, (2013). Disease path of the dead, T: d. Osama al-Qafash, the Egyptian Book House, I 1, the omnipotent.

May, Rolo \& Yalom, Arvin, (1999). Introduction to existential psychotherapy, T: Dr. Adel Mustafa and Ghassan Yaqoub, Dar Al-Nahda Al Arabiya, I 1, Beirut.

May, Rolo, (2014). The Art of Counselling, Souvenir Press, New York.

May,Rollo, (2009).Mans Search For Himself,Norton,first published,New York.

May,Rolo, (2015).The Discovery of Being,Norton \& Company Ltd, London.

Mohammed, Nour Jabbar, (2014). Emotional emptiness and self - transcendence and their relation to future visions of widows, $\mathrm{PhD}$ thesis, University of Diyala, Faculty of Education of Human Sciences, Iraq. 